Research Article

\title{
A Comparative Study on Fracture Characteristics of the Red Sandstone under Water and Nitrogen Gas Fracturing
}

\author{
Yanan Gao $\mathbb{D}^{1,2}$ Feng Gao $\mathbb{D}^{1,2}$ Zekai Wang, ${ }^{1,2}$ and Peng Hou ${ }^{1,2}$ \\ ${ }^{1}$ State Key Laboratory for Geomechanics and Underground Engineering, China University of Mining and Technology, \\ 1 Daxue Road, Xuzhou, Jiangsu 221116, China \\ ${ }^{2}$ School of Mechanics and Civil Engineering, China University of Mining and Technology, 1 Daxue Road, Xuzhou, \\ Jiangsu 221116, China \\ Correspondence should be addressed to Yanan Gao; yngao@cumt.edu.cn
}

Received 20 March 2018; Revised 12 June 2018; Accepted 24 June 2018; Published 10 July 2018

Academic Editor: Mohsen S. Masoudian

Copyright (c) 2018 Yanan Gao et al. This is an open access article distributed under the Creative Commons Attribution License, which permits unrestricted use, distribution, and reproduction in any medium, provided the original work is properly cited.

\begin{abstract}
Because of the disadvantages in fracturing with the water-base fracturing fluids and the development of reservoir reconstruction technology, nonaqueous fracturing fluid plays a more and more important role in the worldwide exploitation of unconventional natural gas. In this paper, the fracturing experiments of the red sandstone by using water and nitrogen gas are firstly carried out, and the breakdown pressures and failure patterns of the red sandstone specimens under different fracturing fluids are compared. Then, based on the governing equations, the fracturing experiments with water and nitrogen gas are modeled by using a finite element method software-COMSOL Multiphysics. The conclusions can be obtained as follows: (1) The breakdown pressure of the nitrogen gas fracturing is $60 \%$ that of the water fracturing. The ultralow viscosity property of nitrogen gas is the reason for this phenomenon. (2) Compared with the water fracturing, the nitrogen gas fracturing causes greater volumetric strain and a more complex fracture pattern in terms of the number, length, and width of the cracks. (3) The numerical results are close to the experimental data. It implies that numerical modeling in this study can be used as a tool for predicting the breakdown pressure and rupture time. (4) After a sensitive study based on the numerical modeling, it can be found that the loading rate will influence the seepage range which dominates the pore pressure distribution and affects the breakdown pressure for the water fracturing. However, for the nitrogen gas fracturing, the breakdown pressure almost does not change with the loading rate as the nitrogen gas can easily penetrate the specimen from the radial direction.
\end{abstract}

\section{State of the Art}

Natural gas is the third largest source of energy in the world after coal and oil. Meanwhile, among the total reserve of natural gas, the amount of unconventional natural gas is far more than that of conventional natural gas [1]. The development of unconventional natural gas not only can alleviate the global energy crisis but also can reduce carbon dioxide emissions and mitigate the global warming [2]. Since the shale gas revolution arose in 2009 [3], more and more attentions have been paid to the unconventional gas production. Because of the richness in unconventional natural gas resource, such as coalbed methane, tight gas, and shale gas $[4,5]$, China is also making great efforts to develop the unconventional gas [6]. However, unconventional natural gas is difficult to exploit due to the low permeability of the formations, such as shale formation. Soeder indicated that the permeability of shale fractures is generally about (0.001 0.1) $\times 10^{-3} \mu \mathrm{m}^{2}$ [7]. Javadpour showed that the permeability of the Shale matrix is $10^{-9} \mu \mathrm{m}^{2}$ orders of magnitude [8]. Since the permeability is too low to exploit, it is necessary to develop the reservoir stimulation technologies to improve the permeability of the formations. Nowadays, the most popular and mature method to increase the productivity in the world is hydraulic fracturing with waterbase fracturing fluids. Such technology mentioned above has played a very important role in the shale gas revolution. However, with the development of nature gas engineering, 
the defects of the fracturing technology with water-base fracturing fluids are exposed gradually, such as (1) water wasting, especially in the areas of water deficient, for example, the Chinese Ordos area, where the large-scale fracturing with water-base fluids is difficult to be implemented; (2) water lock effect and the Jamin effect, which will occur along with the water injection and result in blocking the gas migration channel and impairing the productivity $[9,10]$; and (3) fracturing fluid backflow problem, the fluids contain many chemical ingredients which will cause the unrecoverable damage to the stratum and the underground water pollution [11, 12].

As the drawbacks mentioned above, the fracturing technologies with the water-base fluids have been banned by more and more organizations or countries [13]. Meanwhile, fracturing is still indispensable in nowadays gas and oil engineering [14]. Therefore, technological innovation has become a necessary way for normal unconventional gas production. Nonaqueous fracturing is deemed to be a method that can replace the fracturing with water-base fluids and to solve the water wasting, reservoir damage, and the environmental problem. Meanwhile, nitrogen gas is regarded as a great kind of fracturing fluid that can be used in nonaqueous fracturing. Compared with the water fracturing, the nitrogen gas fracturing has the following advantages: (1) the nitrogen reserves richly in the air, and thus people do not need to pay much attention to the fracturing fluid resource and the fracturing fluid wasting; (2) nitrogen does not react with montmorillonite, and hence the water lock effect and Jamin effect can be avoided; (3) as a gas, nitrogen is easy to discharge, and there is no damage to the reservoir and no gas retention problems; (4) nitrogen can promote desorption of nature gas and increase the productivity [15]; and (5) nitrogen is a safe fluid as it does not react with natural gas.

As early as 1981, Abel used nitrogen gas as a fracturing fluid in the Ohio Shale Formation [16]. The results showed that this technology succeeded in production promotion, even without a propping agent, and it had outperformed other stimulation systems. Wozniak et al. compared the reservoir reform effect of nitrogen gas fracturing, nitrogen foam fracturing, and mixed nitrogen fracturing and found out that nitrogen gas fracturing did best in production promotion with the minimum cost [17].

To make a further understanding of fracture characteristics of the red sandstone under water and nitrogen gas fracturing, in this study, the uniaxial test and Brazilian test are carried out to get the basic parameters of the red sandstone at first. Then, the comparison study between the water fracturing experiment and nitrogen gas fracturing experiment is carried out with the aspects of breakdown pressure, volumetric strain of the specimen, and failure pattern. Afterwards, the numerical method is proposed and validated. Finally, the effects of the loading rate in both the water fracturing experiment and the nitrogen gas fracturing experiment are also investigated.

\section{Experimental Materials and Procedure}

2.1. Specimen Preparation. The intact sandstone blocks are collected from the Shandong Province, China. Cutting work and polishing work of the cylindrical cores are carried out by a diamond cutter with an acute blade and a grinder, respectively. Firstly, the specimens are prepared in general accordance with ISRM $(1978,1983)$. The height and diameter of the test specimens are about $100 \mathrm{~mm}$ and $50 \mathrm{~mm}$. Then, the specimens for the fracturing tests need to be processed further. A central borehole of $10 \mathrm{~mm}$ in diameter and $60 \mathrm{~mm}$ in length is drilled axially from the midpoint of the specimen by using a diamond bit (Figure 1(a)). Afterwards, the surfaces and boreholes of the specimens are cleaned by using the clean water which is a transparent, colorless, tasteless, and neutral liquid. After the dimensions of the prepared specimens are measured, the specimens are placed in a $100^{\circ} \mathrm{C}$ oven for 24 hours. The dry mass of the specimens is obtained after they had been cooled down to room temperature. Finally, the specimens are stored inside heat shrinking PVC jackets.

Through the SEM test, it can be observed that the grains of the red sandstone are loosely arranged and pores exist in the intergrain (Figure 1(b)). Based on the XRD test, it can be found that quartz, feldspar, and mica are the main mineral constituents of the red sandstone (Figure 1(c)).

\subsection{Experiment Equipment. The uniaxial compression tests} and Brazilian disc tests are carried out by using the TAW2000 electro-hydraulic servo-controlled rock mechanic testing system with a load capacity of $2000 \mathrm{kN}$ to obtain the mechanical parameters of the rocks. The gas fracturing tests are performed by using the TAW-2000 electrohydraulic servo-controlled rock mechanic testing system and the highpressure gas fracturing system (Figure 2). The high-pressure gas fracturing system consists of the air compressor, the gas tank, the control cabinet, the booster pump, and the medium gas cylinders.

The maximum values of the output gas pressure and standard flow are $80 \mathrm{MPa}$ and $63 \mathrm{~L} / \mathrm{min}$, respectively. The device, as shown Figure 3, is used to load water pressure on specimens. It is mainly driven by the electric motor and a spiral metal rod.

2.3. Fracturing Experiment Method. The procedure of the fracturing tests is interpreted as follows:

(1) A platen with a double concentric O-ring encircling the central injection port is designed (Figure 4(a)). To prevent gas filtration from the specimen bottom or top, a seal gum with high bond strength is used to seal the specimen bottom and the platen end (Figure $4(\mathrm{~b})$ ). Before the test, the time of air-drying should not be less than $48 \mathrm{~h}$.

(2) Fracturing tests are carried out at room temperature and at a uniaxial stress of $4 \mathrm{MPa}$. Any sealing devices on the sides of the specimen are uninstalled during the tests since the fracturing tests are carried out at uniaxial state. Meanwhile, the axial extensometer and lateral extensometer are attached to the specimen to measure the deformation of the specimen during water or gas injection 

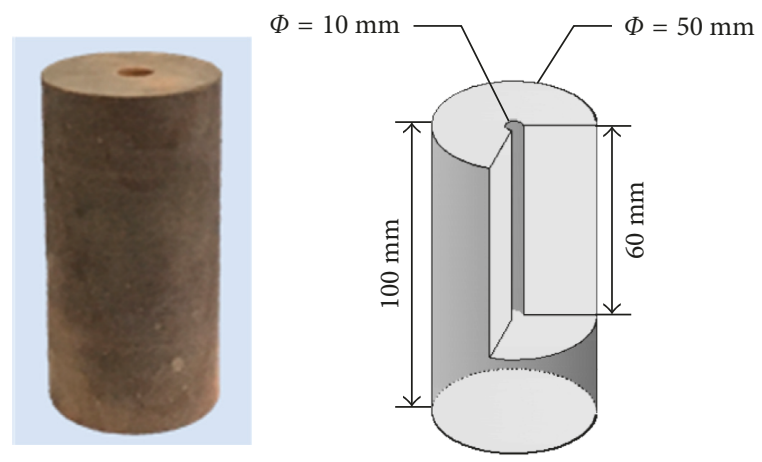

(a)

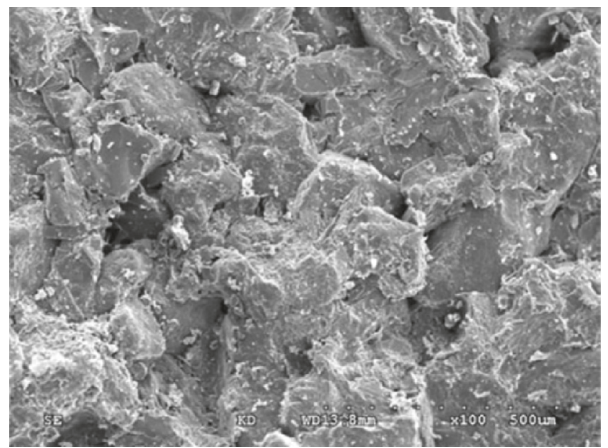

(b)

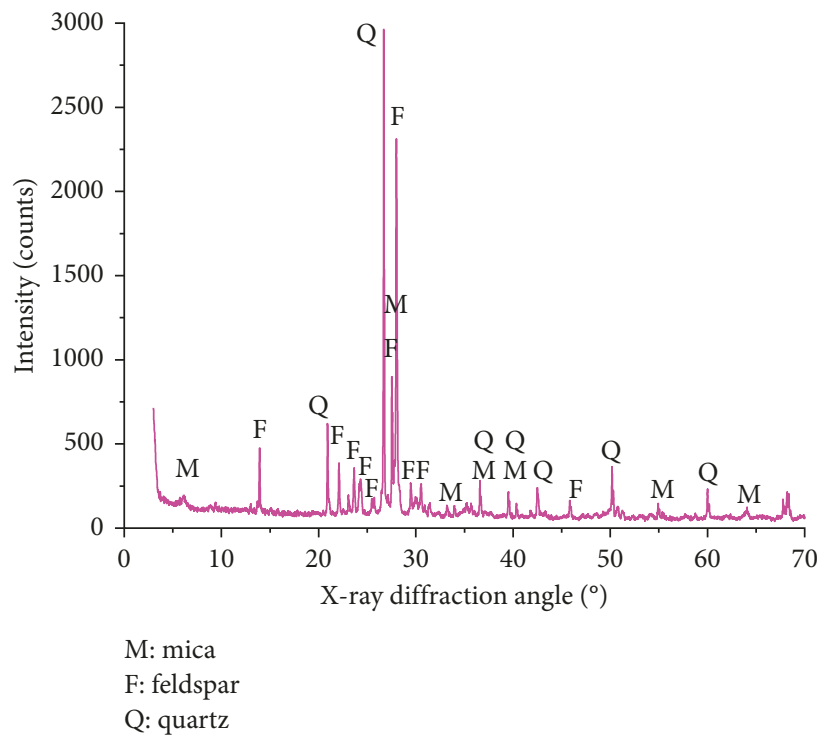

(c)

FIGURE 1: Preparation and mesoscopic tests of the red sandstone specimen. (a) Specimen design. (b) Scanning electron microscope (SEM) pattern of specimen. (c) Analysis of X-ray diffraction.

(3) For the water fracturing test, the water is injected to the tank of the hydraulic (water) loading device firstly. Then the water pressure valve is opened, and the spiral metal rod will move forward to apply the water pressure to the specimen until the specimen to be fractured.

(4) For the nitrogen gas fracturing test, firstly, the air compressor and cold dryer are opened. The gas tank is filled by the compressed air of $1 \mathrm{MPa}$, which is used as the driving gas. Then, the nitrogen cylinder valve is opened to apply load to the nitrogen gas, which is used as the media gas. Afterwards, the booster pump system is started to apply the gas pressure until the specimen to be fractured.

It is important to note that the devices for the water fracturing and gas fracturing are different. Meanwhile, the loading mechanisms and control methods of the water fracturing and gas fracturing are also different. Thus, it can hardly make the loading conditions the same for those two kinds of fracturing tests, such as loading rate.

\subsection{Analysis of Experimental Results}

2.4.1. Basic Mechanical Parameters. As mentioned in Section 1, to have an understanding of the basic mechanical properties of the red sandstone in this paper, we firstly carried out the uniaxial compression test (Figure 5 ). The average values of uniaxial compression strength (UCS), maximum strain, and Young's modules are $89.5 \mathrm{MPa}, 0.005$, and $15 \mathrm{GPa}$, respectively.

Afterwards, the flattened Brazilian disk specimens are employed for testing and evaluating the tensile strength and fracture toughness of the red sandstone. The thickness and diameter of the test specimens are about $20 \mathrm{~mm}$ and $50 \mathrm{~mm}$, and the loading angle is about $20^{\circ}[18,19]$. The failure pattern and load-displacement curves are shown in Figures 6 and 7, respectively.

According to the analytical solutions of the tensile strength and fracture toughness proposed by Wang and Xing [20], the tensile strength and fracture toughness can be written as follows: 


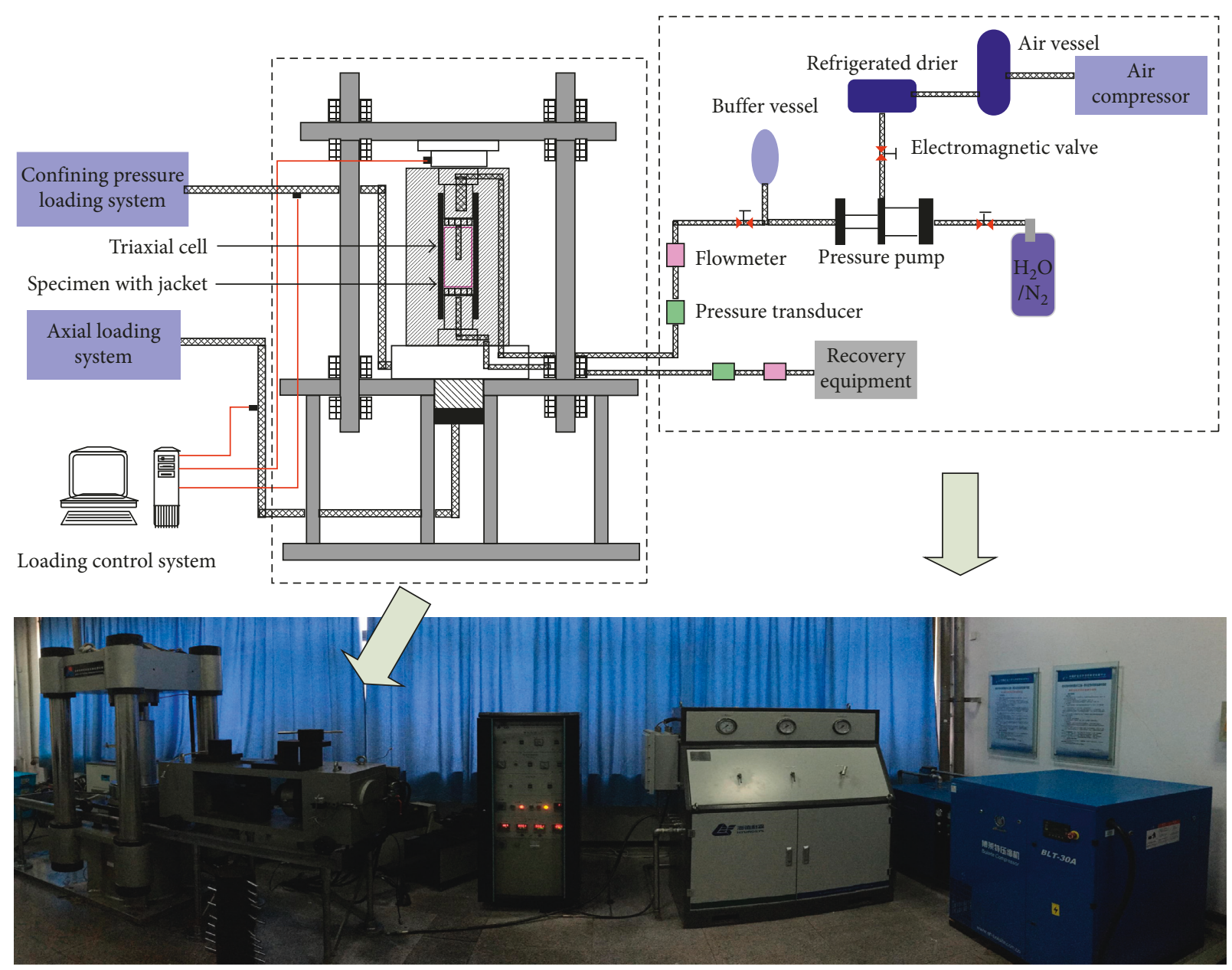

FIgURE 2: Testing equipment.

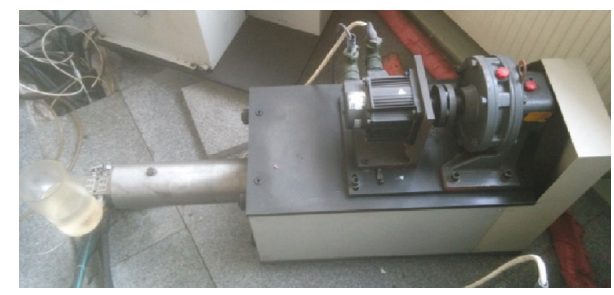

FIgURE 3: Hydraulic (water) pressure loading system.

$$
\begin{aligned}
\sigma_{\mathrm{t}} & =0.96 \frac{2 P_{\mathrm{c}}}{\pi D h}, \\
K_{\mathrm{IC}} & =0.7997 \frac{P_{\min }}{\sqrt{R} h},
\end{aligned}
$$

where $D, R$, and $h$ are the diameter, radius, and thickness of the specimen, respectively; $P_{c}$ is the crucial load, that is, the maximum load during the test and $P_{\min }$ is the local minimum load; and $\sigma_{\mathrm{t}}$ and $K_{\mathrm{IC}}$ are the tensile strength and fracture toughness of the red sandstone, respectively.

Based on (1) and (2) and the measured parameter of the tests (Table 1), the average values of tensile strength and fracture toughness are $4.5 \mathrm{MPa}$ and $0.99 \mathrm{MPa} \cdot \mathrm{m}^{1 / 2}$, respectively.
2.4.2. Fracturing Tests. As shown in Figure 8, the volumetric strain/water pressure (gas pressure)-time curves of $6 \mathrm{spec}-$ imens during water and nitrogen gas fracturing are given, where $\mathrm{W} 1, \mathrm{~W} 2$, and $\mathrm{W} 3$ denote the specimens of the water fracturing, and G1, G2, G3 denote the specimens of nitrogen gas fracturing. For the water fracturing, the pressure loading rates are $0.09552 \mathrm{MPa} / \mathrm{s}, 0.07328 \mathrm{MPa} / \mathrm{s}$, and $0.06368 \mathrm{MPa} / \mathrm{s}$; the breakdown pressures of the specimens are $7.52 \mathrm{MPa}$, 7.38 MPa, and 7.75 MPa. For the nitrogen gas fracturing, the pressure loading rates are $0.03259 \mathrm{MPa} / \mathrm{s}, 0.02254 \mathrm{MPa} / \mathrm{s}$, and $0.01237 \mathrm{MPa} / \mathrm{s}$, and the breakdown pressures of the specimens are $4.0 \mathrm{MPa}, 4.7 \mathrm{MPa}$, and $4.2 \mathrm{MPa}$.

It can be found that the breakdown pressure of the water fracturing is higher than that of the nitrogen gas fracturing. The reason of the phenomenon may be that the breakdown pressure has a strong relationship with the viscosity of fracturing fluid. A lower fluid viscosity will result in lower pressure needed to breakdown the specimen, while a higher fracturing fluid viscosity will require a higher pressure to breakdown the same specimen [21]. As we know, compared with water, nitrogen gas has the property of ultralow viscosity. Thus, it can breakdown the specimen at lower pressure. Because there are many existing microfractures or pores inside the specimen, nitrogen gas can more easily 


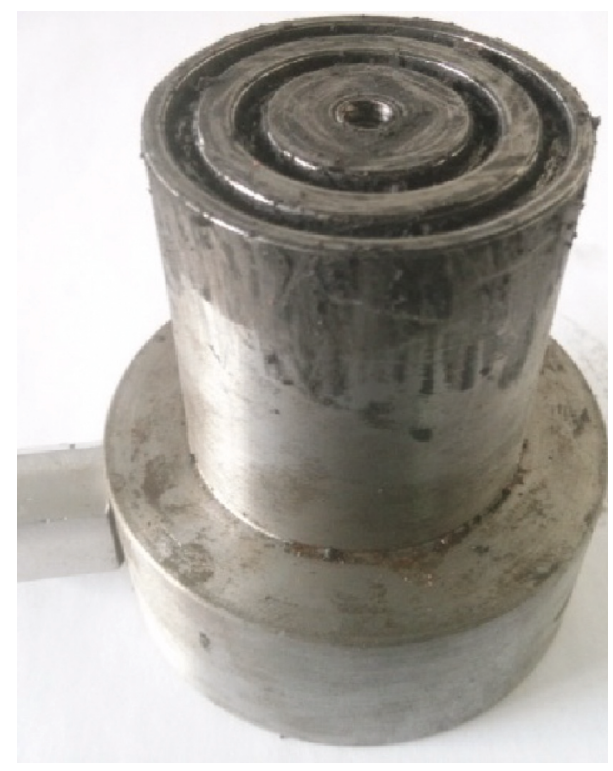

(a)

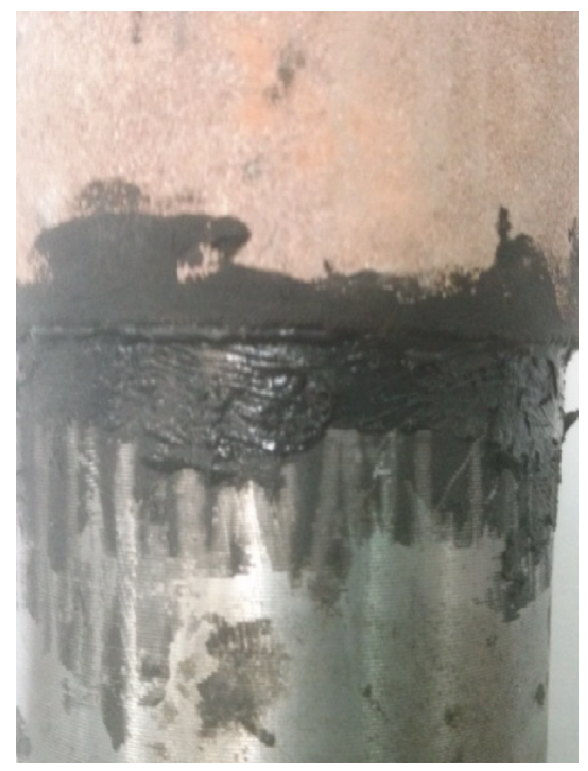

(b)

FIgURE 4: Sealing of the specimen. (a) Platen. (b) Specimen bonded with platen.

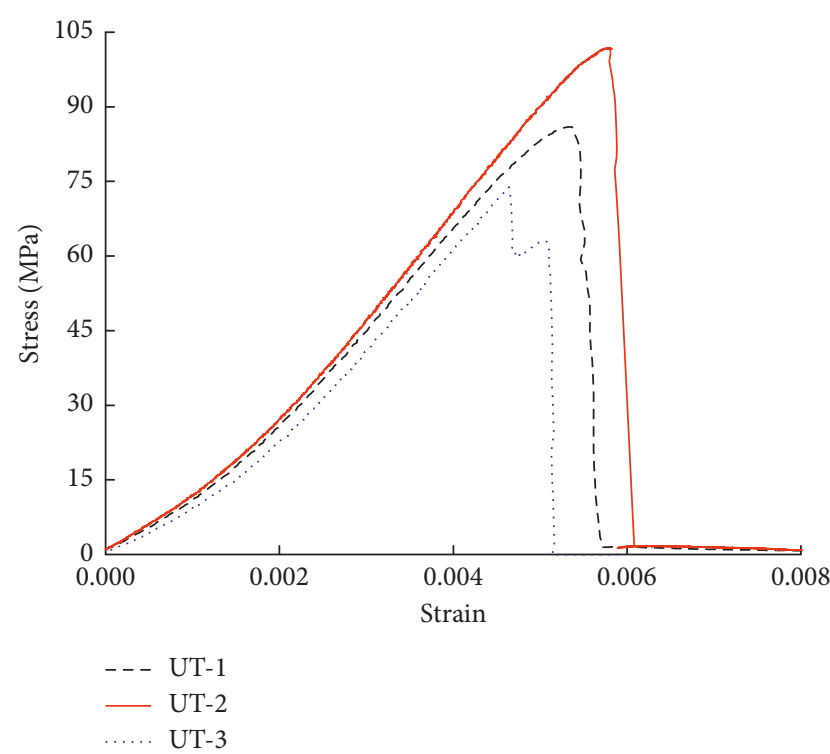

FIgURE 5: Stress-strain curves of specimens under uniaxial compression. UT-1, UT-2, and UT-3 denote the uniaxial compression test of specimens 1,2 , and 3 , respectively.

penetrate the microfractures or pores, which results in transmitting the injection pressure to all the penetrated points. This decreases the strength of the specimen and allows the nitrogen gas to break it at lower pressures [13]. On the contrary, the high-viscosity fluid, such as water, tends to remain with the borehole and less likely to be able to penetrate these microfractures. Therefore, a higher pressure is needed to break the specimen by using the high-viscosity fluid. Meanwhile, because the nitrogen gas can transmit the injection pressure to all the penetrated points, the pore pressure of the specimen of nitrogen gas injection is higher

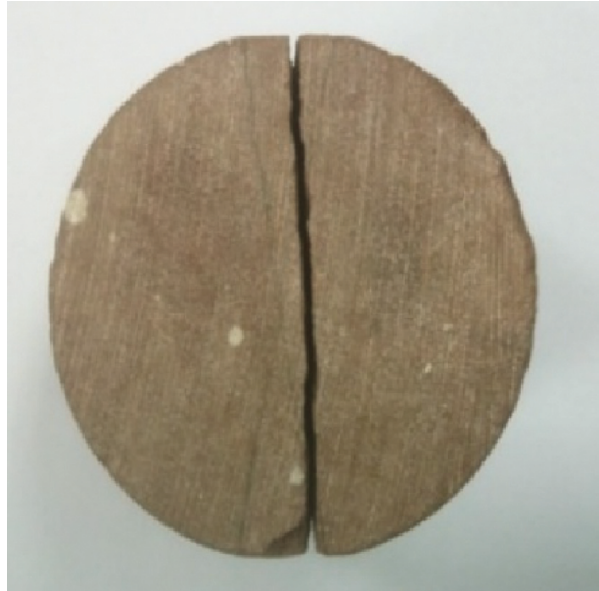

FIGURE 6: Failure pattern of the flattened Brazilian disk specimen.

than that of water injection under the same injection pressure. The stress intensity factor is positively correlated with the pore pressure [22]. Therefore, breaking down the specimen with nitrogen gas will result in a higher stress intensity factor, and a lower breakdown pressure is needed.

However, for both the water fracturing and the nitrogen gas fracturing, the breakdown pressure does not change obviously with the loading rate, which indicates that three loading rates of the experiment do not have a significant effect on the breakdown pressure of the water fracturing or nitrogen gas fracturing.

As shown in Tables 2 and 3, volumetric strain under the nitrogen gas fracturing is much larger than the one under the water fracturing pressure. Note that the volumetric strain is measured at the injection pressure of $4 \mathrm{MPa}$ as the specimen will be fractured if the pressure is higher than $4 \mathrm{MPa}$ under the nitrogen gas fracturing. 


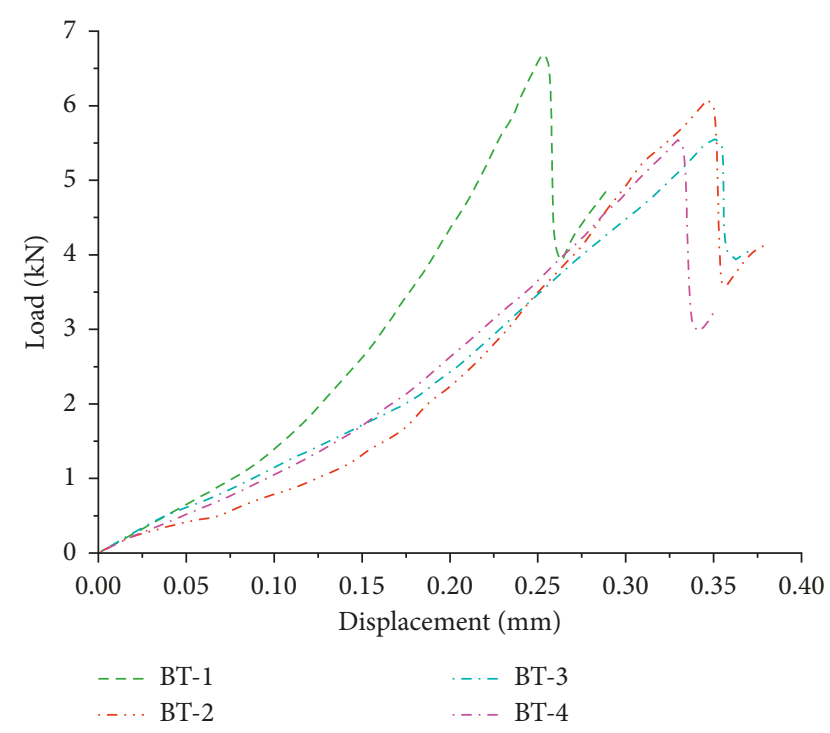

FIGURE 7: Load-displacement curves of the flattened Brazilian disk specimens. BT-1, BT-2, BT-3, and BT-4 denote the Brazilian disc test of specimens $1,2,3$, and 4 , respectively.

TABle 1: Tensile strength and fracture toughness of the red sandstone specimens.

\begin{tabular}{lccccccc}
\hline $\begin{array}{l}\text { Testing } \\
\text { number }\end{array}$ & $\begin{array}{c}D \\
(\mathrm{~mm})\end{array}$ & $\begin{array}{c}R \\
(\mathrm{~mm})\end{array}$ & $\begin{array}{c}H \\
(\mathrm{~mm})\end{array}$ & $\begin{array}{c}P_{\mathrm{c}} \\
(\mathrm{kN})\end{array}$ & $\begin{array}{c}P_{\min } \\
(\mathrm{kN})\end{array}$ & $\begin{array}{c}\sigma_{\mathrm{t}} \\
(\mathrm{MPa})\end{array}$ & $\begin{array}{c}K_{\mathrm{IC}} \\
\left(\mathrm{MPa} \cdot \mathrm{m}^{1 / 2}\right)\end{array}$ \\
\hline 1 & 49.98 & 24.99 & 16.18 & 6.76 & 3.91 & 5.11 & 1.22 \\
2 & 49.92 & 24.96 & 17.70 & 6.34 & 3.20 & 4.39 & 0.91 \\
3 & 49.86 & 24.93 & 16.88 & 5.77 & 3.49 & 4.19 & 1.04 \\
4 & 50.01 & 25.05 & 15.94 & 5.62 & 2.53 & 4.30 & 0.80 \\
\hline
\end{tabular}

The water fracturing and the nitrogen gas fracturing make different failure patterns, as shown in Figure 9, and the failure pattern of the specimen after the nitrogen gas fracturing is more complex. Three main cracks are formed; the cracks propagate through the entire specimen. For each main crack, there are several secondary cracks around it. However, for the specimen under the water fracturing, there are only two symmetrical cracks which do not penetrate through the longitude (axial) of the whole specimen. Meanwhile, it can be observed that the widths of the cracks formed after nitrogen gas fracturing are also larger than those formed after the water fracturing.

\section{Numerical Simulation}

The PDE module in COMSOL Multiphysics is used to carry out the modeling of the water fracturing and the nitrogen gas fracturing. By using MATLAB, a seepage stress-coupling algorithm with the time-expanding seepage boundary is developed. The calculation routine and flow chart are shown in Figures 10 and 11.

3.1. Stress Field. According to the principle of effective stress proposed by Terzaghi and improved by Biot, the relationship between total stress, effective stress, and pore pressure can be written as [23]

$$
\sigma_{i j}=\sigma_{i j}^{\prime}+\beta p \delta_{j}
$$

where $\sigma_{i j}$ is the total stress; $\sigma_{i j}^{\prime}$ denotes the effective stress; $\beta$ is called Biot's coefficient; $\beta=1-\left(K_{\mathrm{b}} / K_{\mathrm{s}}\right), K_{\mathrm{b}}$ is the bulk modulus of porous media and $K_{\mathrm{s}}$ is the bulk modulus of solid framework particles; $p$ is the pore pressure; and $\delta_{j}$ is the identity tensor.

In our fracturing experiments, all specimens are standard cylindrical specimens with a borehole through the midpoint; therefore, the stress field can be illustrated as shown in Figure 12. The equilibrium equation, geometric equations, and physical equations can be written in polar coordinates.

Without volume force, the equilibrium equation combining with principle of effective stress can be written as

$$
\frac{\partial \sigma_{\mathrm{r}}^{\prime}}{\partial r}+\frac{\sigma_{\mathrm{r}}^{\prime}-\sigma_{\theta}^{\prime}}{r}+\frac{\partial(\beta p)}{\partial r}=0,
$$

where $\sigma_{\mathrm{r}}^{\prime}$ is the radial effective stress and $\sigma_{\theta}^{\prime}$ is the circumferential effective stress. The physical equations are

$$
\begin{aligned}
& \sigma_{\mathrm{r}}^{\prime}=2 G\left(\varepsilon_{\mathrm{r}}+\frac{\nu}{1-2 \nu} \varepsilon_{\mathrm{v}}\right), \\
& \sigma_{\theta}^{\prime}=2 G\left(\varepsilon_{\theta}+\frac{\nu}{1-2 \nu} \varepsilon_{\mathrm{v}}\right),
\end{aligned}
$$

where $\varepsilon_{\mathrm{r}}$ is the radial effective strain, $\varepsilon_{\theta}$ is the circumferential effective strain, $G$ is the shear modulus, and $\varepsilon_{\mathrm{v}}$ is the volumetric strain.

As the axial boundary is fixed, the axial strain is 0 . Thus, $\varepsilon_{\mathrm{v}}=\varepsilon_{\mathrm{r}}+\varepsilon_{\theta}$. The geometric equations can be written as follows:

$$
\begin{gathered}
\varepsilon_{\mathrm{r}}=-\frac{\partial u_{\mathrm{r}}}{\partial r}, \\
\varepsilon_{\theta}=-\frac{u_{\mathrm{r}}}{r},
\end{gathered}
$$

where $u_{\mathrm{r}}$ is the radial displacement.

Because the whole model is axisymmetric, the circumferential displacement $u_{\theta}$ is 0 . Finally, the stress field equations can be written as

$$
\frac{E(1-\nu)}{(1+\nu) \cdot(1-2 \nu)}\left(\frac{\partial^{2} u_{\mathrm{r}}}{\partial r^{2}}+\frac{1}{r} \frac{\partial u_{\mathrm{r}}}{\partial r}-\frac{1}{r^{2}} u_{\mathrm{r}}\right)-\beta \frac{\partial p}{\partial r}=0 .
$$

3.2. Seepage Field. According to the definition of porosity, the porosity $\varphi$ can be written as

$$
\begin{aligned}
\varphi & =\frac{V_{\mathrm{p}}}{V_{\mathrm{b}}}=\frac{V_{\mathrm{p} 0}+\Delta V_{\mathrm{p}}}{V_{\mathrm{b} 0}+\Delta V_{\mathrm{b}}}=1-\frac{V_{\mathrm{s} 0}+\Delta V_{\mathrm{s}}}{V_{\mathrm{b} 0}+\Delta V_{\mathrm{b}}} \\
& =1-\frac{V_{\mathrm{s} 0}\left(1+\left(\Delta V_{\mathrm{s}} / V_{\mathrm{s} 0}\right)\right)}{V_{\mathrm{b} 0}\left(1+\left(\Delta V_{\mathrm{b}} / V_{\mathrm{b} 0}\right)\right)} \\
& =1-\frac{\left(1-\varphi_{0}\right)\left(1+\left(\Delta V_{\mathrm{s}} / V_{\mathrm{s} 0}\right)\right)}{1-\varepsilon_{\mathrm{v}}},
\end{aligned}
$$




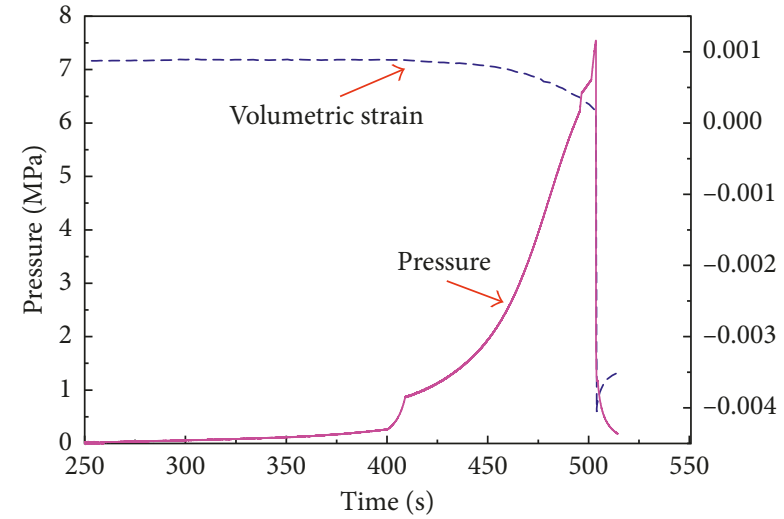

(a)

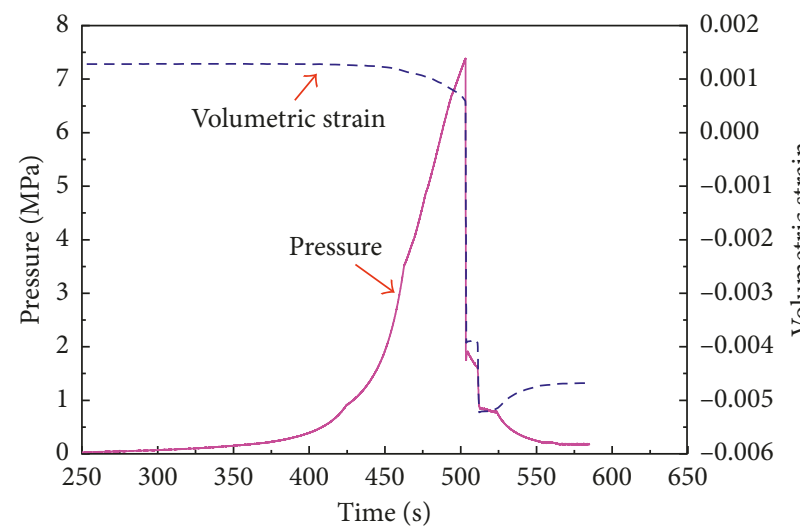

(c)

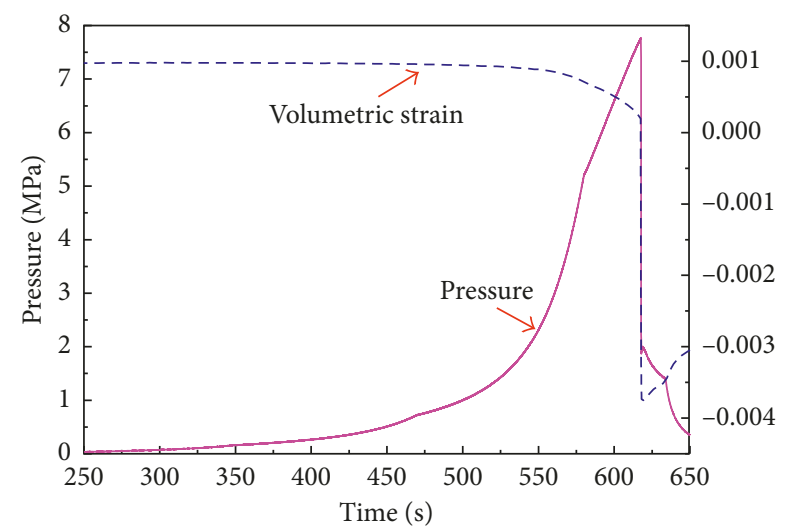

(e)

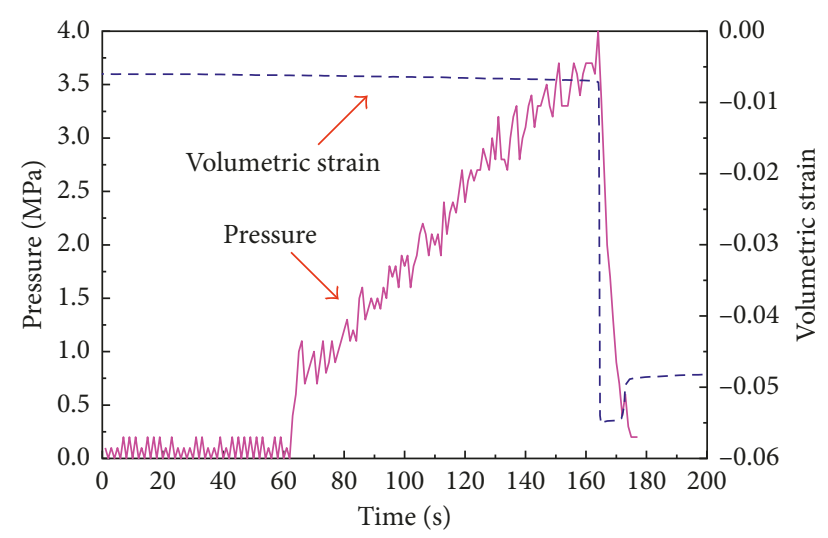

(b)

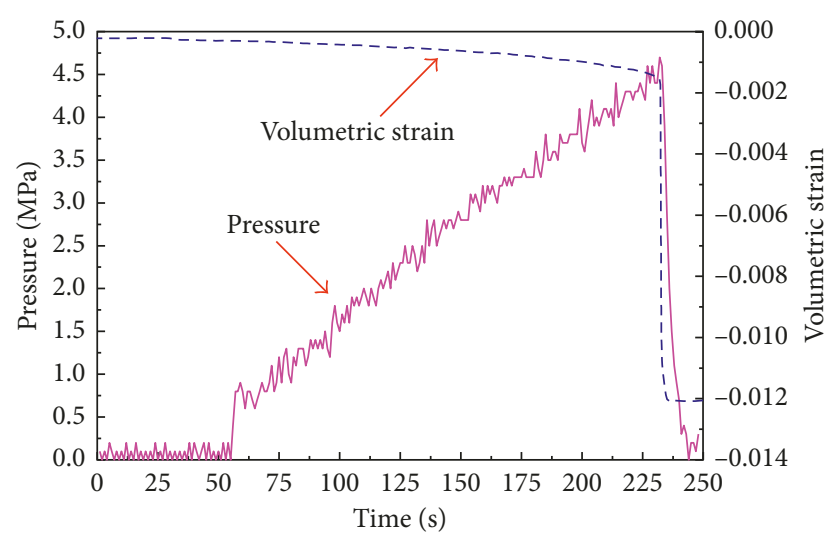

(d)

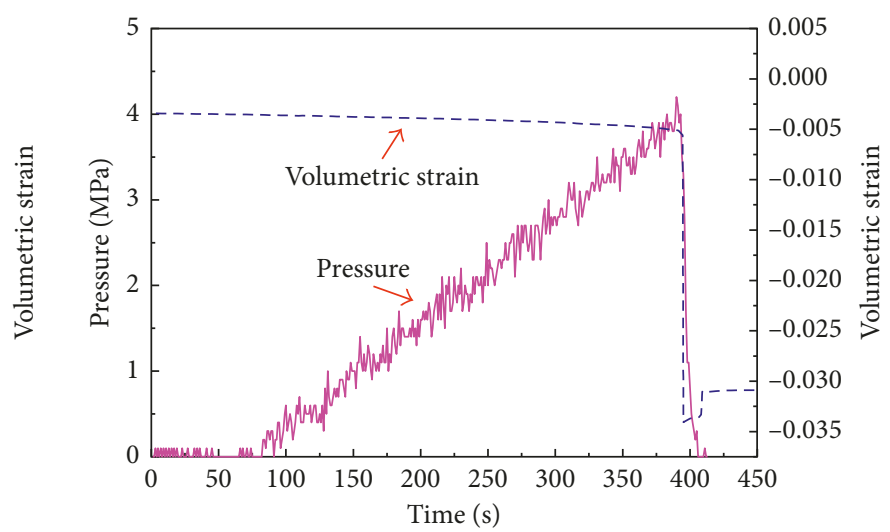

(f)

FIGURE 8: Plots of volumetric strain and pressure with time during fracturing. (a) W1 loading rate: 0.09552 MPa/s. (b) G1 loading rate: $0.03259 \mathrm{MPa} / \mathrm{s}$. (c) W2 loading rate: $0.07328 \mathrm{MPa} / \mathrm{s}$. (d) G2 loading rate: $0.02254 \mathrm{MPa} / \mathrm{s}$. (e) W3 loading rate: $0.06368 \mathrm{MPa} / \mathrm{s}$. (f) G3 loading rate: $0.01237 \mathrm{MPa} / \mathrm{s}$.

TABLE 2: The volumetric strain of the specimens under the water fracturing pressure $(4 \mathrm{MPa})$.

\begin{tabular}{lcc}
\hline Specimen number & Loading rate $(\mathrm{MPa} / \mathrm{s})$ & Volumetric strain \\
\hline W1 & 0.09552 & -0.00020 \\
W2 & 0.07328 & -0.00017 \\
W3 & 0.06368 & -0.00018 \\
\hline
\end{tabular}

TABLE 3: The volumetric strain of the specimens under the nitrogen gas fracturing pressure $(4 \mathrm{MPa})$.

\begin{tabular}{lcc}
\hline Specimen number & Loading rate $(\mathrm{MPa} / \mathrm{s})$ & Volumetric strain \\
\hline G1 & 0.03259 & -0.0010 \\
G2 & 0.02254 & -0.0013 \\
G3 & 0.01237 & -0.0017 \\
\hline
\end{tabular}




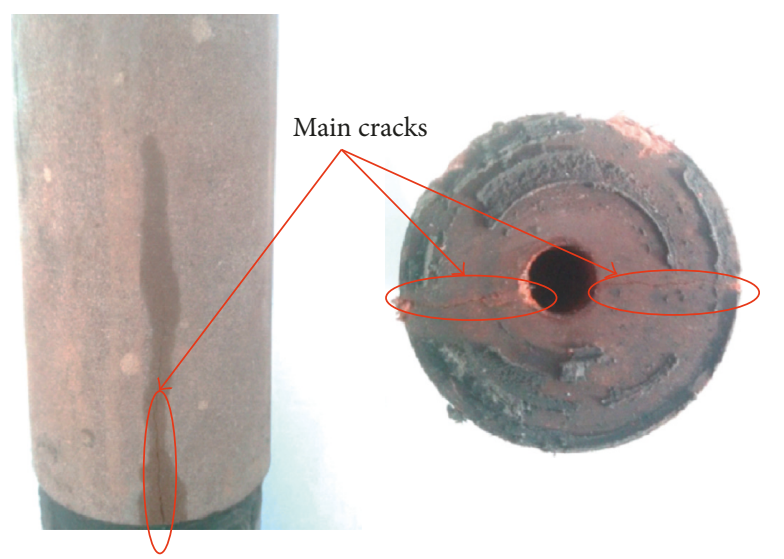

(a)

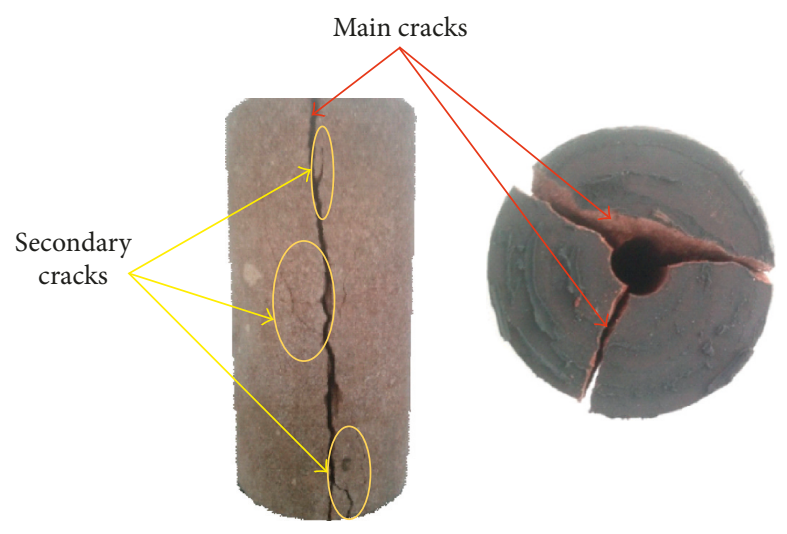

(b)

FIGURE 9: Failure patterns after (a) the water fracturing and (b) the nitrogen gas fracturing.

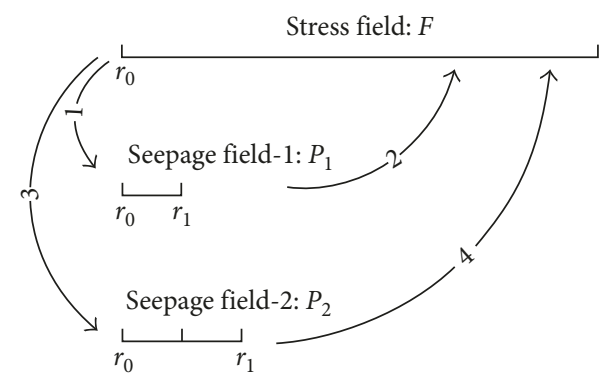

FIGURE 10: Computation routine.

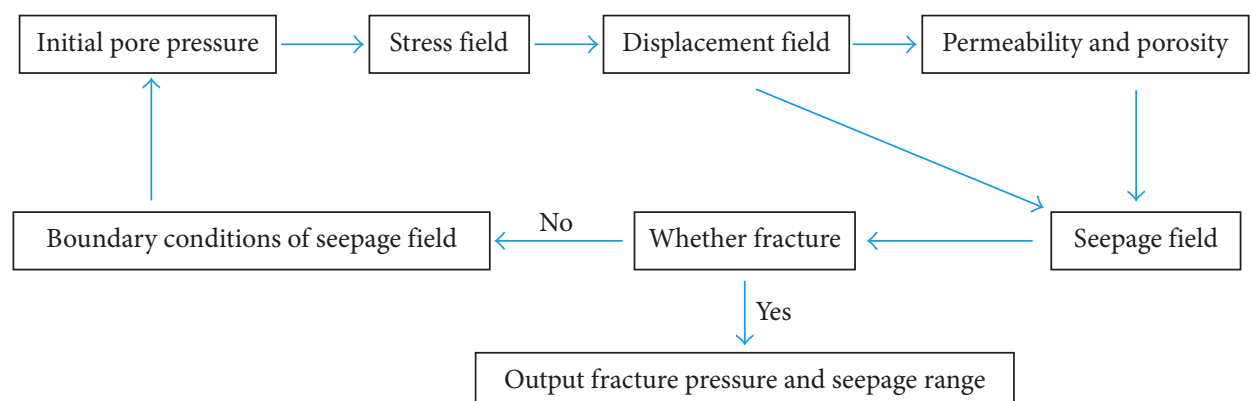

Figure 11: The flow chart of simulation.

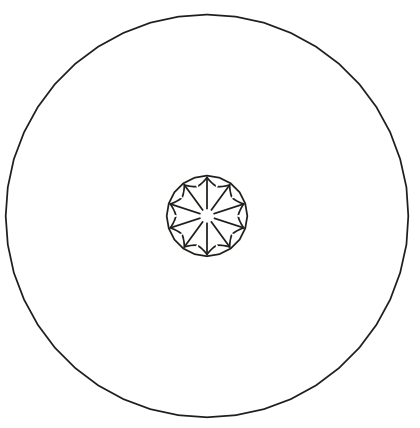

Figure 12: Calculation model of the stress field. where $V_{\mathrm{p}}, V_{\mathrm{p} 0}$, and $\Delta V_{\mathrm{p}}$ are the pore volume, initial pore volume, and the increment of the pore volume; $V_{\mathrm{b}}, V_{\mathrm{b} 0}$, and $\Delta V_{\mathrm{b}}$ are the appearance volume, initial appearance volume, and the increment of appearance volume; $V_{\mathrm{s} 0}$ and $\Delta V_{\mathrm{s}}$ are the volume of initial solid skeleton in porous media and the increment of solid skeleton; $\varphi_{0}=V_{\mathrm{p} 0} / V_{\mathrm{b} 0}$ is the initial porosity; and $\varepsilon_{\mathrm{v}}=-\Delta V_{\mathrm{b}} / V_{\mathrm{b} 0}$ is the volumetric strain.

It is assumed that the deformation of solid skeleton is caused only by the pore stress:

$$
\frac{\Delta V_{\mathrm{s}}}{V_{\mathrm{s} 0}}=\frac{-\Delta p}{K_{\mathrm{s}}} .
$$

where $\Delta p$ is the increment of pore stress. 
The permeability $K$ can be written according to the Kozeny-Carman equation [24] as

$$
K=\frac{\varphi^{3}}{c S^{2}}
$$

where $c$ is the dimensionless coefficient which can be give an approximate value of 5 [24] and $S$ is the specific surface area of the solid phase.

Since the change of the surface area is very small, the permeability $K$ can be written based on the initial permeability $K_{0}$ as [25]

$$
K=\frac{K_{0}}{\left(1-\varepsilon_{\mathrm{v}}\right)}\left[1-\frac{\varepsilon_{\mathrm{v}}-\left(\Delta p\left(1-\varphi_{0}\right) / K_{\mathrm{s}}\right)}{\varphi_{0}}\right]^{3} .
$$

Based on the conservation of mass, $\nabla\left[\rho_{\mathrm{s}}(1-\varphi) \vec{V}_{\mathrm{s}}\right]+$ $\partial\left[\rho_{\mathrm{s}}(1-\varphi)\right] / \partial t=0$, where $\rho_{\mathrm{s}}$ means the density of rock solid skeleton and $\vec{V}_{\mathrm{s}}$ means the absolute speed of rock solid skeleton particles. Considering that $(1-\varphi) \rho_{\mathrm{s}} \gg \rho_{\mathrm{s}}\left|\vec{V}_{\mathrm{s}}\right| \gg$ $(1-\varphi)\left|\vec{V}_{s}\right|$, the continuity equation of rock solid skeleton particles can be written as

$$
(1-\varphi) \rho_{\mathrm{s}} \nabla \vec{V}_{\mathrm{s}}+(1-\varphi) \frac{\partial \rho_{\mathrm{s}}}{\partial t}-\rho_{\mathrm{s}} \frac{\partial \varphi}{\partial t}=0
$$

As the same as rock solid skeleton particles, the continuity equation of fluid can be simplified as

$$
\varphi \rho_{\mathrm{f}} \nabla \vec{V}_{\mathrm{f}}+\varphi \frac{\partial \rho_{\mathrm{f}}}{\partial t}+\rho_{\mathrm{f}} \frac{\partial \varphi}{\partial t}=0
$$

where $\rho_{\mathrm{f}}$ is the density of fluid or gas and $\vec{V}_{\mathrm{f}}$ is the absolute speed of fluid or gas.

On the contrary, gas can be compressed easily, so the continuity equation of gas is

$$
\varphi \vec{V}_{\mathrm{f}} \nabla \rho_{\mathrm{f}}+\varphi \rho_{\mathrm{f}} \nabla \vec{V}_{\mathrm{f}}+\varphi \frac{\partial \rho_{\mathrm{f}}}{\partial t}+\rho_{\mathrm{f}} \frac{\partial \varphi}{\partial t}=0
$$

Finally, the seepage field equation of fluid under fluidsolid coupling described by pore pressure $p$ is

$$
\frac{\partial \varepsilon_{\mathrm{v}}}{\partial t}-\frac{1}{\mu}\left[\nabla(K \nabla p)+\frac{K}{r} \frac{\partial p}{\partial r}\right]+\left(\frac{1-\varphi}{K_{\mathrm{s}}}+\frac{\varphi}{K_{\mathrm{f}}}\right) \frac{\partial p}{\partial t}=0 .
$$

The seepage field equation of gas is

$$
\begin{aligned}
& -\frac{K}{\mu p}\left(\frac{\partial p}{\partial r}\right)^{2}+\frac{\varphi}{p} \frac{\partial u_{\mathrm{r}}}{\partial t} \frac{\partial p}{\partial r}+\frac{\partial \varepsilon_{\mathrm{v}}}{\partial t}-\frac{1}{\mu}\left[\nabla(K \nabla p)+\frac{K}{r} \frac{\partial p}{\partial r}\right] \\
& \quad+\left(\frac{1-\varphi}{K_{s}}+\frac{\varphi}{p}\right) \frac{\partial p}{\partial t}=0 .
\end{aligned}
$$

3.3. Fracture Criterion. The stress intensity factor is employed to evaluate whether fracture happens or not as follows:

$$
K_{1}+K_{2}+K_{3} \geq K_{\text {IC }}
$$

The whole stress intensity factor of breakdown pressure is divided into three parts: $K_{1}$ is the stress intensity factor of

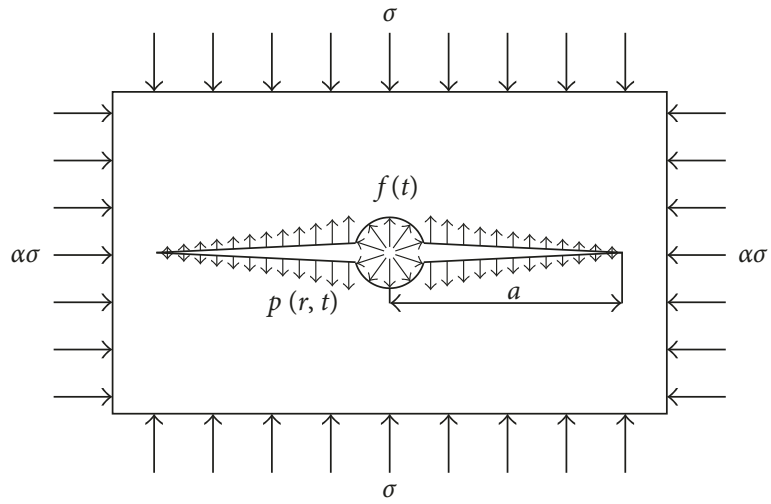

FIGURE 13: Calculation model of the stress intensity factor.

in situ stress; $K_{2}$ is the stress intensity factor of borehole stress; and $K_{3}$ is the stress intensity factor in pore stress.

The stress intensity factor can be obtained as follows (shown in Figure 13):

$$
\begin{aligned}
& K_{1}=-0.9872 \sigma \sqrt{\pi a}, \\
& K_{2}=0.205 f(t) \sqrt{\pi a}, \\
& K_{3}=\int_{r_{0}}^{r_{1}} \frac{p(r, t)}{\sqrt{\pi a}}\left(\sqrt{\frac{a+r}{a-r}}+\sqrt{\frac{a-r}{a+r}}\right) d r,
\end{aligned}
$$

where $\sigma$ is the vertical stress; $\alpha$ is the lateral stress ratio; $a$ is the pore length, $f(t)$ is the pressure of the borehole that changes with time; $p(r, t)$ is the pore stress that changes with time and position; and $r_{0}$ and $r_{1}$ are the radius of the borehole and the influenced radius of pore pressure.

3.4. Results and Analysis. In order to verify the fracture criterion in the water fracturing and the nitrogen gas fracturing and the accuracy of the calculation method, COMSOL Multiphysics is used to simulate the water fracturing and the nitrogen gas fracturing tests of the red sandstone under different loading rates. The relevant parameters are listed in Table 4 [26, 27].

3.4.1. Comparison Study of Numerical Modeling and Experiments. The computational and experimental results are listed in Tables 5 and 6 . It can be concluded that the values of the rupture time and breakdown pressure calculated by numerical approach are close to those obtained from experiments. Therefore, the computational model can be taken as a reliable tool for predicting the breakdown pressure and the rupture time.

Based on the numerical calculation, the pore pressure in the process of the water fracturing and the nitrogen gas fracturing can be obtained under different fracturing pressures and different loading rates. The distribution curves of the pore pressure during the fracturing process are plotted in Figure 14.

Figure 14 shows that the pore pressure distribution curves during water fracturing and the nitrogen gas fracturing are different. The breakdown pressure of the water fracturing is higher than that of nitrogen gas fracturing. The 
TABLE 4: Calculation parameters.

\begin{tabular}{lcc}
\hline Physical quantity & Unit & Value \\
\hline Drilling radius & $\mathrm{m}$ & 0.005 \\
Sample radius & $\mathrm{m}$ & 0.025 \\
Young's modulus & $\mathrm{GPa}$ & 5.6 \\
Poisson ratio & & 0.1 \\
Biot's coefficient & $\mathrm{GPa}$ & 0.9 \\
Compressive volumetric modulus of skeleton & $\mathrm{GPa}$ & 200 \\
Compressed volumetric modulus of water & & 2.2 \\
Initial porosity & $\mathrm{m}^{2}$ & 0.1 \\
Initial permeability & $\mathrm{MPa}$ & $1 e-16$ \\
Initial pore pressure & $\mathrm{m}$ & 0.101 \\
Crack length & $\mathrm{MPa} \mathrm{m}$ & 0.013 \\
Fracture toughness & $\mathrm{Pa} \mathrm{s}$ & 0.99 \\
Viscosity of water & $\mathrm{Pa} \mathrm{s}$ & $1 e-3$ \\
Viscosity of nitrogen & $\mathrm{MPa} / \mathrm{s}$ & $0.178 e-4$ \\
Loading rates of the water fracturing & $\mathrm{MPa} / \mathrm{s}$ & $0.09552(\mathrm{~W} 1), 0.07328$ (W2), 0.06368 (W3) \\
Loading rates of the nitrogen gas fracturing & & 0.03259 (G1), $0.02254(\mathrm{G} 2), 0.01237$ (G3) \\
\hline
\end{tabular}

TABLE 5: The numerical and experimental values of rupture time and breakdown pressure (water fracturing).

\begin{tabular}{lccc}
\hline Specimen number & Method & Rupture time (s) & Breakdown pressure (MPa) \\
\hline \multirow{2}{*}{ W1 } & Numerical modeling & 76 & 7.36 \\
& Experiment & 82.4 & 7.52 \\
W2 & Numerical modeling & 96 & 7.14 \\
& Experiment & 102.2 & 7.38 \\
W3 & Numerical modeling & 109 & 7.04 \\
& Experiment & 119.9 & 7.75 \\
\hline
\end{tabular}

TABLE 6: The numerical and experimental values of rupture time and breakdown pressure (nitrogen gas fracturing).

\begin{tabular}{lccc}
\hline Specimen number & Method & Rupture time (s) & Breakdown pressure (MPa) \\
\hline \multirow{2}{*}{ G1 } & Numerical modeling & 140.0 & 4.664 \\
& Experiment & 153.2 & 4.0 \\
G2 & Numerical modeling & 202.4 & 4.663 \\
& Experiment & 226.5 & 4.7 \\
G3 & Numerical modeling & 374.6 & 4.662 \\
& Experiment & 389.6 & 4.2 \\
\hline
\end{tabular}

nitrogen gas has penetrated through the specimen from the radial direction in $40 \mathrm{~s}$; however, the maximum penetration length is only about $0.012 \mathrm{~m}$ under the water fracturing.

The difference mentioned above may be caused by the different permeation capacity of the water and the nitrogen gas. As we know, compared with the water, the nitrogen gas has the properties of lower viscosity. The nitrogen gas can quickly penetrate through the specimen from the radial direction. On the contrary, water can only permeate to a part of the specimen from the radial direction. Thus, for the nitrogen gas fracturing, the gradient of pore pressure drop is lower, and the stress intensity factor is higher than that under the water fracturing at a certain the injection pressure. Therefore, the values of breakdown pressure under the nitrogen gas fracturing are lower than those under the water fracturing. This is also consistent with the data obtained in the experiments.

Figure 15 shows that, for the different loading rates of the water fracturing, the seepage ranges are, respectively, $11.6 \mathrm{~mm}$, $12.2 \mathrm{~mm}$, and $12.5 \mathrm{~mm}$. The difference of the seepage ranges under the maximum loading rate and the minimum loading rate is only $0.9 \mathrm{~mm}$. Therefore, the pore pressure distribution at each breakdown pressure of different loading rates is similar, and the values of breakdown pressure under each loading rate are close. On the contrary, for the nitrogen gas fracturing, the nitrogen gas can easily penetrate the specimen from the radial direction. Once the nitrogen gas penetrates through the specimen, the seepage boundary can be taken as fixed. Thus, the pore pressure distribution changes little with the loading rate. The loading rate only influences the rupture time. The higher loading rate leads to the shorter rupture time.

The seepage rate can be determined by the gradient of the penetration range-time curve (Figure 15). The values of seepage rate are listed in Table 7 . It can be observed that, for either the water fracturing or the nitrogen gas fracturing, the seepage rate increases with the loading rate.

3.4.2. Study on Loading Rate Effect. Based on the results of Section 3.4.1, the loading rate has little effect on the breakdown pressure for both the water fracturing and the 

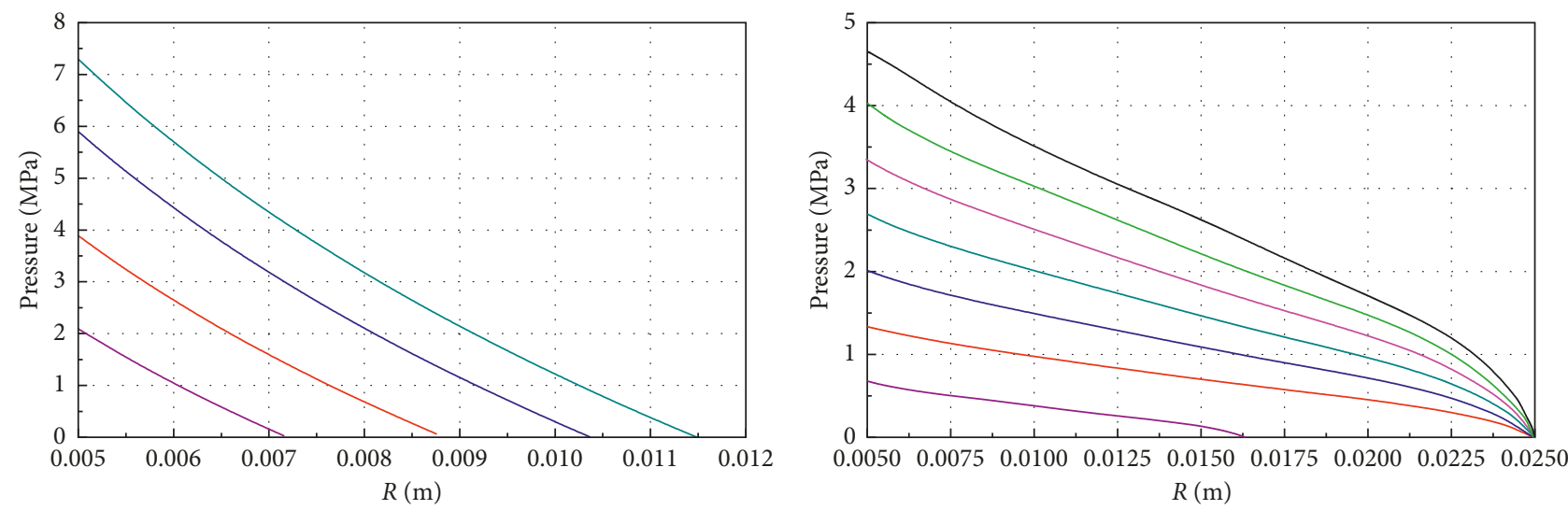

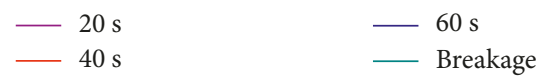

(a)

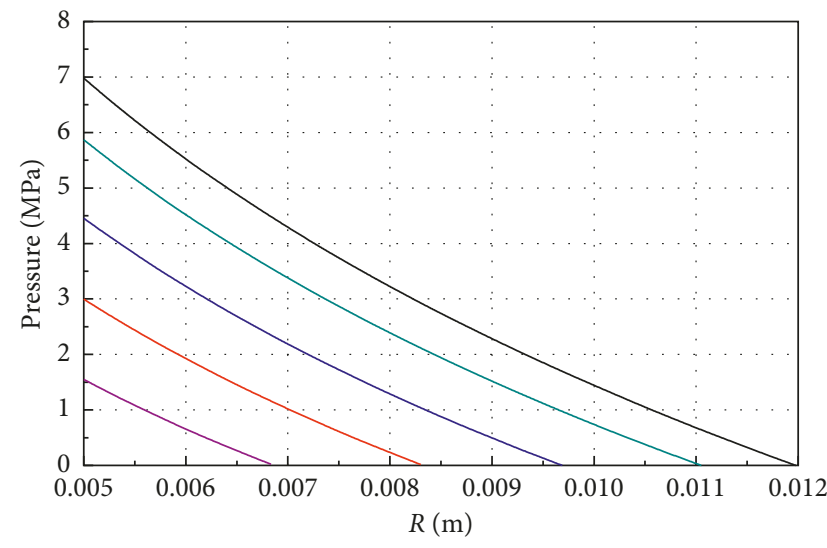

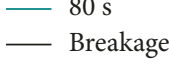

(c)

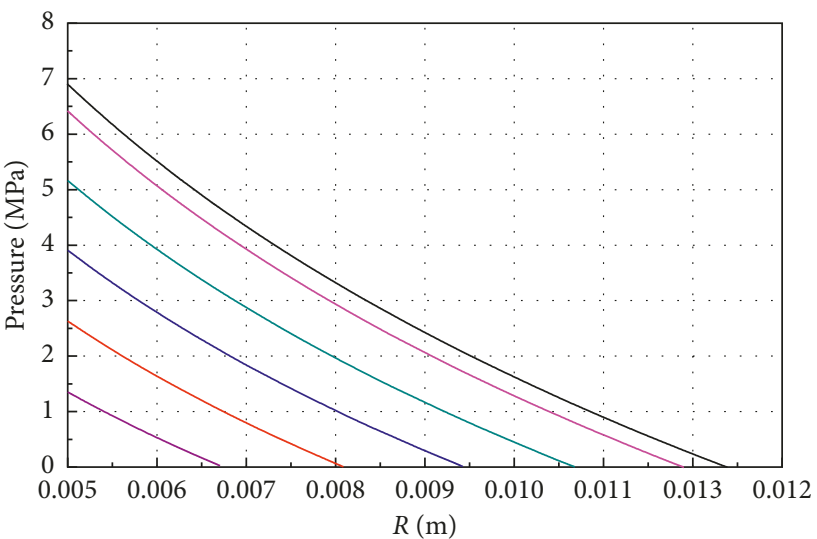

(e)

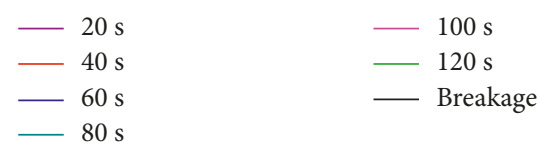

(b)
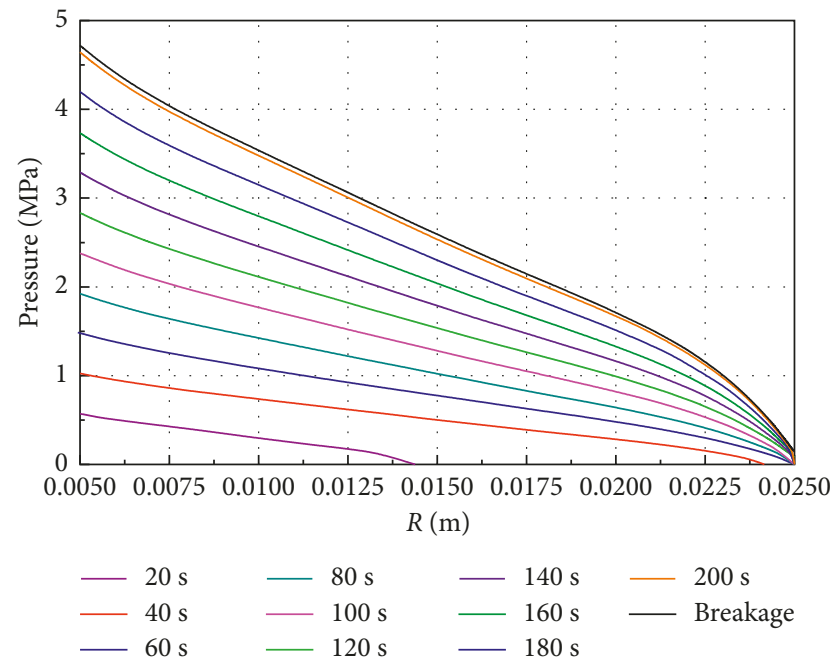

(d)

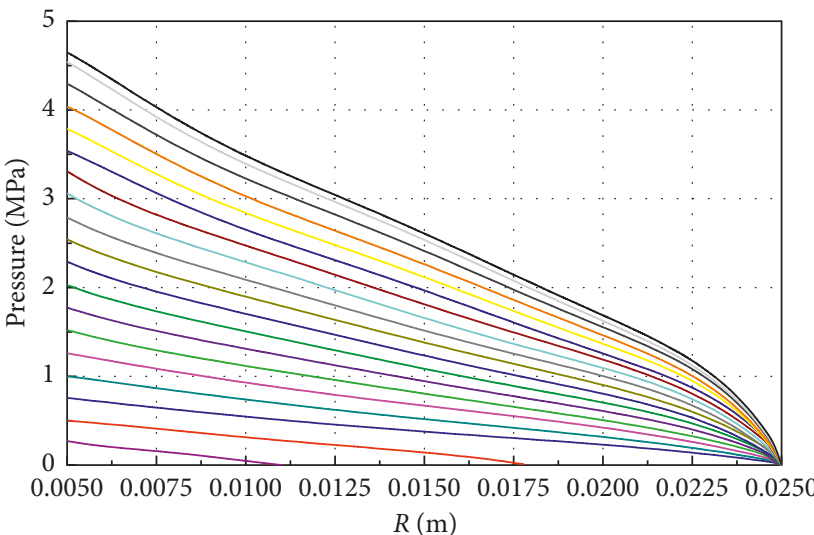

$-20 \mathrm{~s}-100 \mathrm{~s}-180 \mathrm{~s}-260 \mathrm{~s}-340 \mathrm{~s}$
$40 \mathrm{~s}-120 \mathrm{~s}-200 \mathrm{~s}-280 \mathrm{~s}-360 \mathrm{~s}$
$-60 \mathrm{~s}-140 \mathrm{~s}-220 \mathrm{~s}-300 \mathrm{~s}-$ Breakage
$-80 \mathrm{~s}-160 \mathrm{~s}-240 \mathrm{~s}-320 \mathrm{~s}$

(f)

Figure 14: Plots of pore pressure distribution during fracturing (I). (a) W1, (b) G1, (c) W2, (d) G2, (e) W3, and (f) G3. 


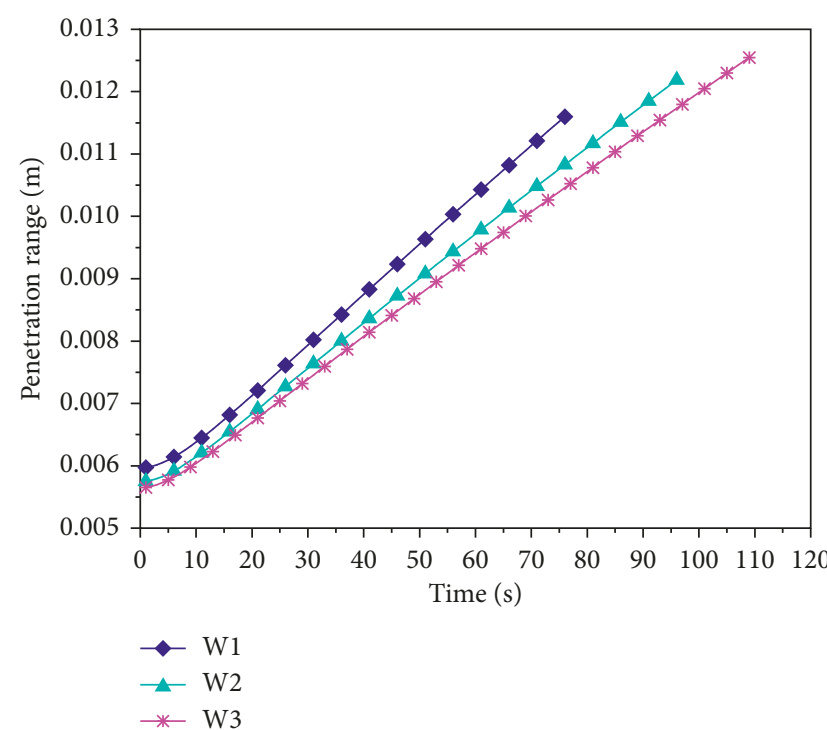

(a)

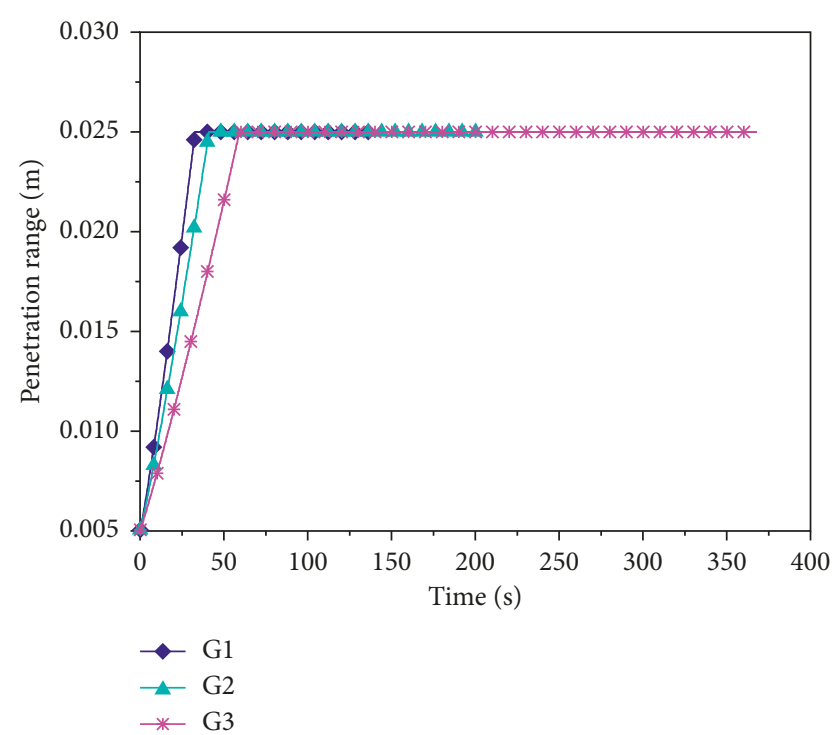

(b)

FIGURE 15: Plots of the seepage range with time during fracturing (I). (a) Water fracturing. (b) Nitrogen gas fracturing.

TABLE 7: Results of seepage rate (I).

\begin{tabular}{lcc}
\hline Specimen number & Method & Seepage rate $(\mathrm{mm} / \mathrm{s})$ \\
\hline W1 & Numerical modeling & 0.0786 \\
W2 & Numerical modeling & 0.0703 \\
W3 & Numerical modeling & 0.0659 \\
G1 & Numerical modeling & 0.7621 \\
G2 & Numerical modeling & 0.6068 \\
G3 & Numerical modeling & 0.4223 \\
\hline
\end{tabular}

nitrogen gas fracturing under our experimental condition. The reason may be that (1) the loading rate does not have a significant effect on seepage range for the water fracturing; (2) for the nitrogen gas fracturing, the seepage range is constant as the nitrogen gas can penetrate the specimen easily, and the seepage boundary can be taken as fixed.

However, the loading rates for the water fracturing and the nitrogen gas fracturing are not consistent in Section 2.4.2; for example, the loading rates of $\mathrm{W} 1$ and $\mathrm{G} 1$ are different. As mentioned in Section 2.3, the loading rates for the water fracturing and the nitrogen gas fracturing can hardly be the same because of the equipment condition. Meanwhile, the numerical method is validated to be reliable in Section 3.4.1. Therefore, the loading rate effect is investigated in this section by using numerical modeling, with the same loading rate for the water fracturing and the nitrogen gas fracturing.

Moreover, for the water fracturing, the seepage range changes with the loading rate although the difference is not obvious. It implies that the loading rate may affect the seepage range. If the loading rate varies greatly in the water fracturing, the seepage range may vary greatly, and the loading rate may have a significant effect on the breakdown pressure. Therefore, three loading rates, $0.5 \mathrm{MPa} / \mathrm{s}\left(\mathrm{W}^{\prime}\right.$, $\left.\mathrm{G} 1^{\prime}\right), 0.05 \mathrm{MPa} / \mathrm{s}\left(\mathrm{W} 2^{\prime}, \mathrm{G} 2^{\prime}\right)$, and $0.005 \mathrm{MPa} / \mathrm{s}\left(\mathrm{W} 3^{\prime}, \mathrm{G}^{\prime}\right)$, are selected to investigate the loading rate effect.
TABLE 8: The numerical results of rupture time and breakdown pressure with the water fracturing.

\begin{tabular}{lccc}
\hline $\begin{array}{l}\text { Specimen } \\
\text { number }\end{array}$ & Method & $\begin{array}{c}\text { Rupture } \\
\text { time }(\mathrm{s})\end{array}$ & $\begin{array}{c}\text { Breakdown } \\
\text { pressure }(\mathrm{MPa})\end{array}$ \\
\hline $\mathrm{W} 1^{\prime}$ & $\begin{array}{c}\text { Numerical } \\
\text { modeling }\end{array}$ & 15.8 & 8.6 \\
$\mathrm{~W} 2^{\prime}$ & $\begin{array}{c}\text { Numerical } \\
\text { modeling }\end{array}$ & 135 & 6.8 \\
$\mathrm{~W}^{\prime}$ & $\begin{array}{c}\text { Numerical } \\
\text { modeling }\end{array}$ & 1053 & 5.36 \\
\hline
\end{tabular}

TABle 9: The numerical results of rupture time and breakdown pressure with the nitrogen gas fracturing.

\begin{tabular}{lccc}
\hline $\begin{array}{l}\text { Specimen } \\
\text { number }\end{array}$ & Method & $\begin{array}{c}\text { Rupture } \\
\text { time }(\mathrm{s})\end{array}$ & $\begin{array}{c}\text { Breakdown } \\
\text { pressure (MPa) }\end{array}$ \\
\hline $\mathrm{G1}^{\prime}$ & $\begin{array}{c}\text { Numerical } \\
\text { modeling }\end{array}$ & 9.6 & 4.80 \\
$\mathrm{G} 2^{\prime}$ & $\begin{array}{c}\text { Numerical } \\
\text { modeling }\end{array}$ & 91.6 & 4.67 \\
$\mathrm{G} 3^{\prime}$ & $\begin{array}{c}\text { Numerical } \\
\text { modeling }\end{array}$ & 911.8 & 4.66 \\
\hline
\end{tabular}

The values of rupture time and breakdown pressure are summarized in Tables 8 and 9. For the water fracturing, the breakdown pressures of the water fracturing are 8.60 MPa, 6.80 MPa, and 5.36 MPa under the loading rates of $0.5 \mathrm{MPa} / \mathrm{s}, 0.05 \mathrm{MPa} / \mathrm{s}$, and $0.005 \mathrm{MPa} / \mathrm{s}$. A higher loading rate results in a higher breakdown pressure. And the rupture time increases from $15.8 \mathrm{~s}$ to $1053 \mathrm{~s}$ when the loading rate decreases from $0.5 \mathrm{MPa} / \mathrm{s}$ to $0.005 \mathrm{MPa} / \mathrm{s}$. When the loading rate varies greatly, the seepage range varies greatly. The loading rate has a significant effect on the breakdown pressure. Meanwhile, from Figures 16 and 17, it can be observed that the loading rate of the water fracturing varies greatly, and the seepage range extends obviously. The 


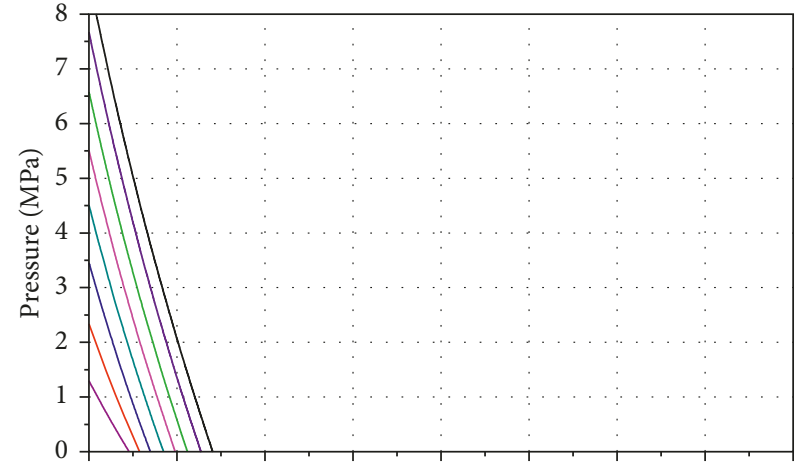

$\begin{array}{lllllllll}0.0050 & 0.0075 & 0.0100 & 0.0125 & 0.0150 & 0.0175 & 0.0200 & 0.0225 & 0.0250\end{array}$ $R(\mathrm{~m})$

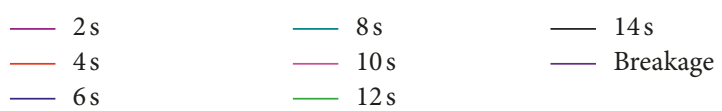

(a)
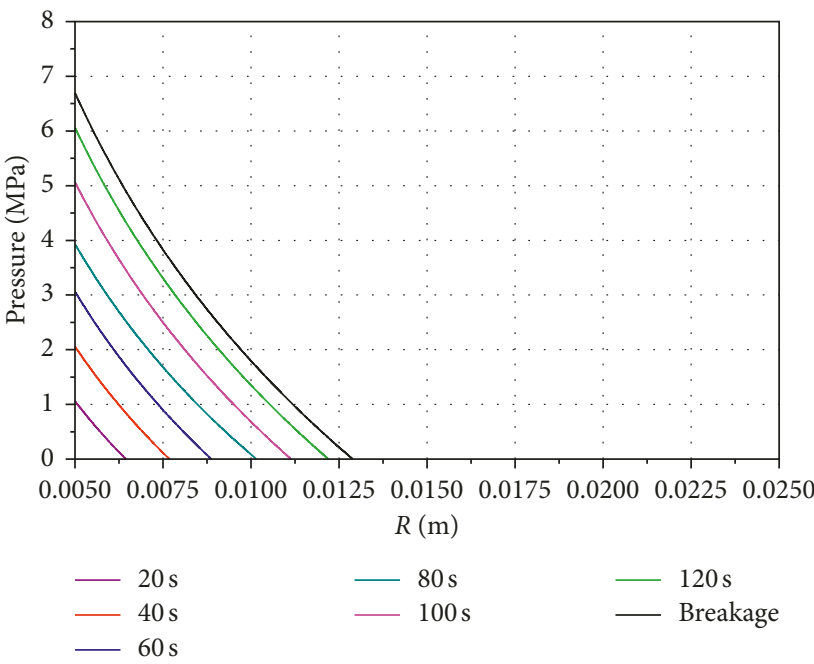

(c)

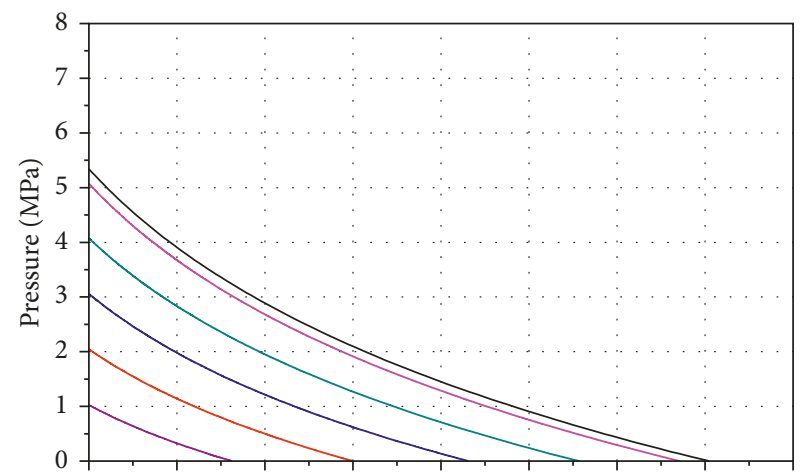

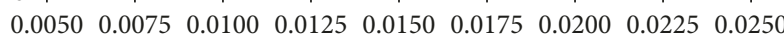
$R(\mathrm{~m})$
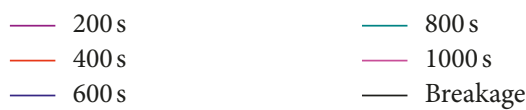

(e)

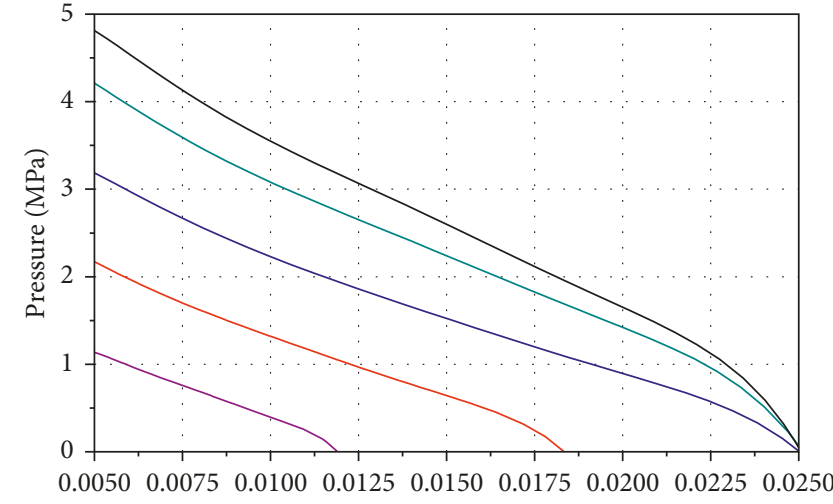
$R(\mathrm{~m})$

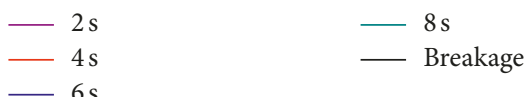

(b)
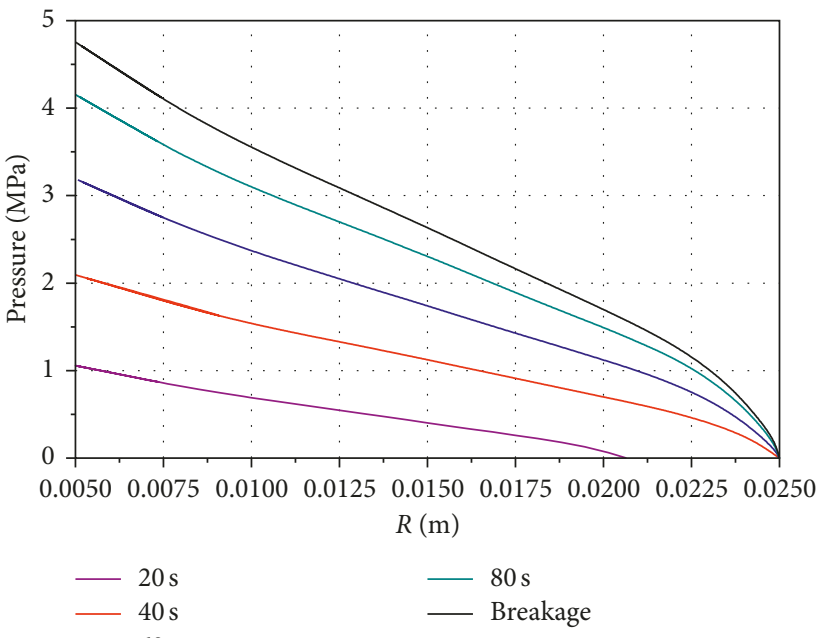

(d)

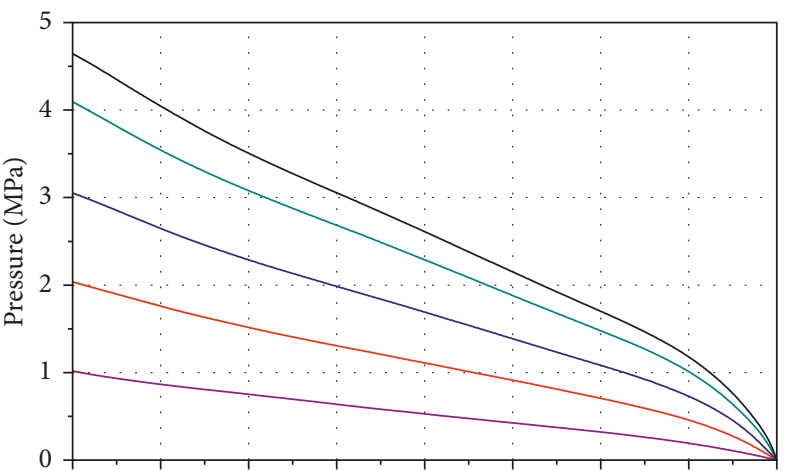

$\begin{array}{lllllllll}0.0050 & 0.0075 & 0.0100 & 0.0125 & 0.0150 & 0.0175 & 0.0200 & 0.0225 & 0.0250\end{array}$ $R(\mathrm{~m})$

$200 \mathrm{~s}$
$-\quad 400 \mathrm{~s}$
$-600 \mathrm{~s}$

$-800 \mathrm{~s}$

_ Breakage

(f)

FIgURE 16: Plots of pore pressure distribution during fracturing (II). (a) W1', (b) G1', (c) W2', (d) G2', (e) W3', and (f) G3'. 


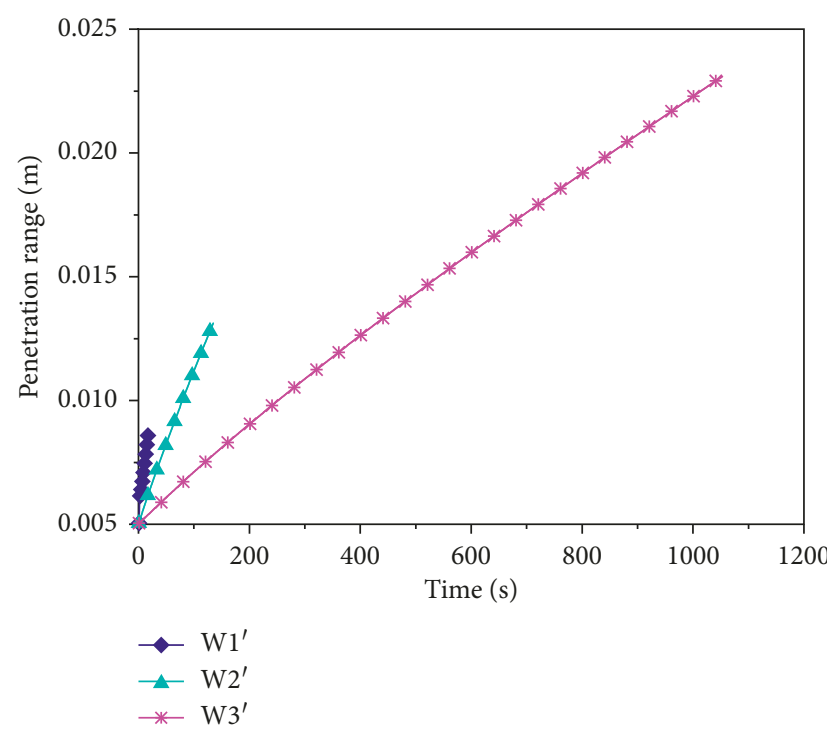

(a)

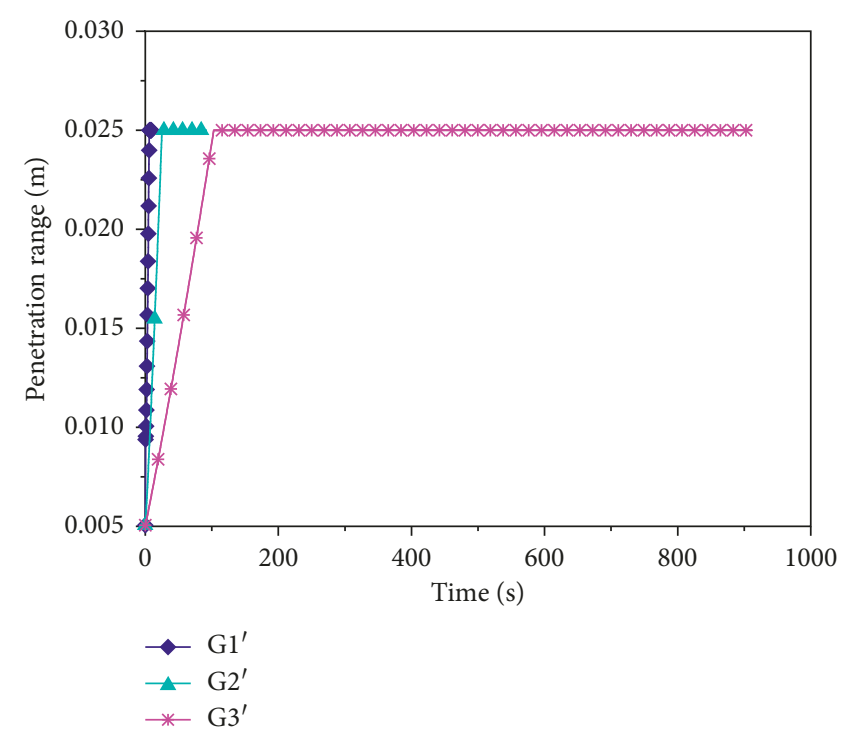

(b)

FIgURE 17: Plots of the seepage range with time during fracturing (II). (a) Water fracturing. (b) Nitrogen gas fracturing.

TABLE 10: Results of the seepage rate (II).

\begin{tabular}{lcc}
\hline Specimen number & Method & Seepage rate $(\mathrm{mm} / \mathrm{s})$ \\
\hline W1' & Numerical modeling & 0.1877 \\
W2' & Numerical modeling & 0.0596 \\
W3 $^{\prime}$ & Numerical modeling & 0.0169 \\
G1 $^{\prime}$ & Numerical modeling & 3.8462 \\
G2 $^{\prime}$ & Numerical modeling & 0.9921 \\
G3 $^{\prime}$ & Numerical modeling & 0.2427 \\
\hline
\end{tabular}

maximum penetration distance of $\mathrm{W} 1^{\prime}, \mathrm{W} 2^{\prime}$, and $\mathrm{W} 3^{\prime}$ are $8.7 \mathrm{~mm}, 13.1 \mathrm{~mm}$, and $23.1 \mathrm{~mm}$, respectively. Therefore, the pore pressure distribution varies obviously, and the gradient of pressure drop, which causes the change of breakdown pressure, varies significantly.

However, for the nitrogen gas fracturing, the nitrogen gas can penetrate through the specimen from the radial direction under each loading rate. Hence, the breakdown pressure of the water fracturing and the seepage range do not change obviously. The breakdown pressures under different loading rates of the nitrogen gas fracturing are all about 4.70 MPa.

Similar to Table 7 , the values of the seepage rate under the three loading rates $(0.5 \mathrm{MPa} / \mathrm{s}, 0.05 \mathrm{MPa} / \mathrm{s}$, and $0.005 \mathrm{MPa} / \mathrm{s}$ ) are listed in Table 10. It can be obtained that the seepage rate increases obviously with the loading rate for both the water fracturing and nitrogen gas fracturing.

\section{Conclusions}

In this study, the fracturing behavior of the red sandstone under water fracturing and the nitrogen gas fracturing are investigated by experiments and numerical modeling. The conclusions can be summarized as follows:

(1) Based on the fracturing tests of the red sandstone with water and nitrogen gas, it can be found that breakdown pressure of the water fracturing is higher than the one under the nitrogen gas fracturing. The breakdown pressure of the nitrogen gas fracturing is about $60 \%$ that of the water fracturing.

(2) The reason of the phenomenon mentioned above is that the nitrogen gas has the property of ultralow viscosity. The nitrogen gas can transmit the injection pressure to all the penetrated points, and the pore pressure is higher. Thus, a lower breakdown pressure is needed to breakdown the specimen.

(3) The volumetric strain of the specimen in nitrogen gas fracturing is larger than that in hydraulic fracturing. Meanwhile, the crack network formed under the nitrogen gas fracturing is more sufficient than that under the water fracturing.

(4) The breakdown pressure and rupture time of the water fracturing and the nitrogen gas fracturing calculated by the numerical method are close to those obtained from the experimental data. It implies that the numerical method can be a reliable tool for predicting the breakdown pressure and the rupture time.

(5) To investigate the loading rate effect on the breakdown pressure and the rupture time, a sensitive study based on three loading rates $(0.5 \mathrm{MPa} / \mathrm{s}, 0.05 \mathrm{MPa} / \mathrm{s}$, and $0.005 \mathrm{MPa} / \mathrm{s}$ ) is carried out by numerical modeling. For the water fracturing, the loading rate will influence the seepage range; therefore, it will have a significant effect on pore pressure distribution and the breakdown pressure. A higher loading rate results in a higher breakdown pressure. On the contrary, for the nitrogen gas fracturing, the nitrogen gas can easily penetrate the specimen from the radial direction; thus, the seepage boundary can be taken as fixed. The breakdown pressure almost does not 
change with the loading rate. And a higher loading rate results in a shorter rupture time and a higher seepage rate.

\section{Data Availability}

Data supporting this research article are available from the corresponding author on request.

\section{Conflicts of Interest}

The authors declare that they have no conflicts of interest.

\section{Acknowledgments}

This project was supported by the Fundamental Research Funds for the Central Universities (no. 2018QNA33). The authors acknowledge the support of the China University of Mining and Technology.

\section{References}

[1] H. Chen, "Reserves and development status of global unconventional natural gas," Fault-Block Oil and Gas Field, vol. 17, no. 4, pp. 439-442, 2010.

[2] J. Chen and X. Chen, “A preliminary study on China's long and medium-term strategic goals for reducing carbon emissions(IV) - prospect for NG use in China and analysis of carbon emission reduction," Sino-Global Energy, vol. 211, no. 1, pp. 1822-1825, 2011.

[3] R. S. Middleton, R. Gupta, J. D. Hyman, and H. S. Viswanathan, "The shale gas revolution: barriers, sustainability, and emerging opportunities," Applied Energy, vol. 199, pp. 88-95, 2017.

[4] US Energy Information Administration, Technically Recoverable Shale Oil and Shale Gas Resources: China, 2013, https://www.eia.gov/analysis/studies/worldshalegas/pdf/ China_2013.pdf.

[5] N. Wang, L. Fei, D. Lei, and B. Zeng, "Analysis of unconventional gas resources distribution and development status in China," Petroleum Geology and Recovery Efficiency, vol. 22, no. 1, pp. 26-31, 2015.

[6] J. Du and X. Li, "The PetroChina Co., Ltd., "12th Five-Year" oil and gas exploration and discovery of the "13th Five-Year" outlook," Petroleum Exploration in China, vol. 21, no. 2, pp. 1-15, 2016.

[7] D. J. Soeder, "Porosity and permeability of Eastern Devonian gas shale," in Proceedings of Unconventional Gas Technology Symposium of the Society of Petroleum Engineers, Louisville, KY, USA, May 1986.

[8] F. Javadpour, "Nanopores and apparent permeability of gas flow in mudrocks (shales and siltstone)," Journal of Canadian Petroleum Technology, vol. 48, no. 8, pp. 16-21, 2009.

[9] N. Lai, Z. Ye, X. Liu, J. Yang, and J. Zhang, "Laboratory study on water lock damage in low permeability tight sandstone gas reservoir," Natural Gas Industry, vol. 25, no. 4, pp. 125-127, 2005.

[10] F. Wang, "Study and application on protection techniques for low-permeability tight sandstone gas reservoir," Natural Gas Industry, vol. 26, no. 10, pp. 89-91, 2006.

[11] G. T. Llewellyn, F. Dorman, J. Westland et al., "Evaluating a groundwater supply contamination incident attributed to Marcellus shale gas development," Proceedings of the National Academy of Sciences, vol. 112, no. 20, pp. 6325-6330, 2015.
[12] R. E. Jackson, A. W. Gorody, B. Mayer, J. W. Roy, M. C. Ryan, and D. R. Van Stempvoort, "Groundwater protection and unconventional gas extraction: the critical need for field-based hydrogeological research," Ground Water, vol. 51, no. 4, pp. 488-510, 2013.

[13] H. Xie, F. Gao, Y. Ju, L. Xie, Y. Yang, and J. Wang, "Novel idea of the theory and application of 3D volume fracturing for stimulation of shale gas reservoirs," Chinese Science Bulletin, vol. 61, pp. 36-46, 2016.

[14] R. W. Howarth, A. Ingraffea, and T. Engelder, "Natural gas: should fracking stop?," Nature, vol. 477, no. 7364, pp. 271-275, 2011.

[15] X. Ni, B. Jia, and Y. Cao, "Study on EOR of hydraulic fracturing with nitrogen injection in coalbed methane well," Mining Safety and Environmental Protection, vol. 39, no. 1, pp. 1-3, 2012.

[16] J. Abel, "Application of nitrogen fracturing in the Ohio Shale," in Proceedings of the SPE Eastern Regional Meeting, Morgantown, WV, USA, October 1981.

[17] G. Wozniak, R. T. Vacto, and D. Hina, "Completion optimization in the Lower Huron Shale in Kentucky," in Proceedings of the SPE Eastern Regional Meeting, Morgantown, WV, USA, October 2010.

[18] Q. Wang and Z. Wu, "Determination of elastic modulus, tensile strength and fracture toughness of brittle rock by platform Brazil disk specimen-second part: test results," Rock Mechanic and Rock Engineer, vol. 23, no. 2, pp. 199-204, 2004.

[19] D. Li and L. N. Y. Wong, "The Brazilian disc test for rock mechanics applications: review and new insights," Rock Mechanics and Rock Engineering, vol. 46, no. 2, pp. 269-287, 2013.

[20] Q. Wang and L. Xing, "Determination of fracture toughness KIC, by using the flattened Brazilian disk specimen for rocks," Engineering Fracture Mechanics, vol. 64, no. 2, pp. 193-201, 1999.

[21] A. M. Gomaa, Q. Qi, R. Maharidge, S. Nelson, and T. Reed, "New insights into hydraulic fracturing of shale formations," in Proceedings of the International Petroleum Technology Conference, ITPC-17594, Doha, Qatar, January 2014.

[22] T. L. Anderson, Fracture Mechanics: Fundamentals and Applications, CRC Press, Taylor and Francis Group, Boca Raton, FL, USA, 2005.

[23] M. A. Boit, "General theory of three-dimensional consolidation," Journal of Applied Physics, vol. 12, pp. 155-164, 1941.

[24] P. C. Carman, "Fluid flow through granular beds," Transactions of the Institution of Chemical Engineers, vol. 15, pp. 150-167, 1937.

[25] B. Lin, "Experimental and theoretical study on the difference of rock breakdown pressure between hydraulic and pneumatic fracturing," M.S. thesis, China University of Mining and Technology, Xuzhou, China, 2015.

[26] B. Zhao, D. Liu, and K. Xue, "Experimental study on uniaxial direct tensile properties of Chongqing red sandstone," Engineering Investigation, vol. 4, pp. 9-12, 2011.

[27] X. Liu, H. Gao, and L. Liang, "Influence of temperature confining pressure on porosity and permeability of low permeability sandstone," Rock Mechanics and Rock Engineering, vol. 30, pp. 3771-3778, 2011. 


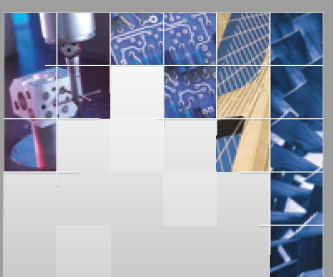

\section{Enfincering}
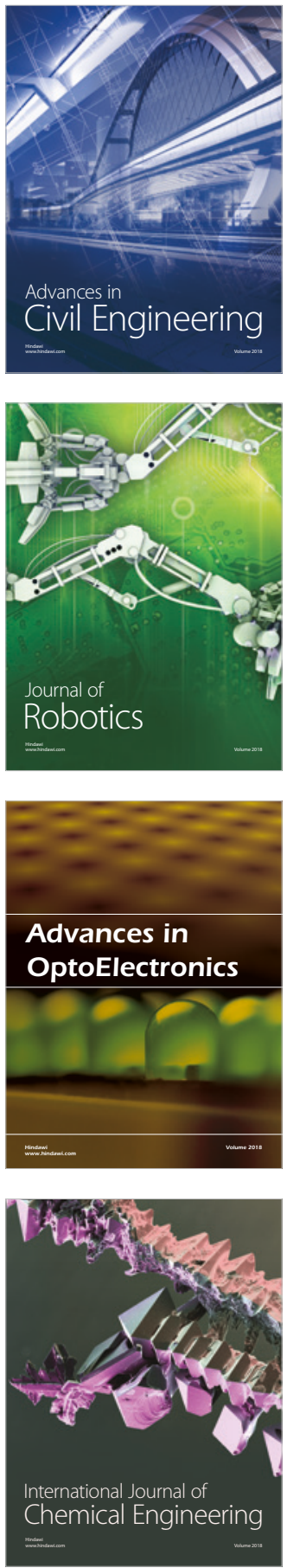

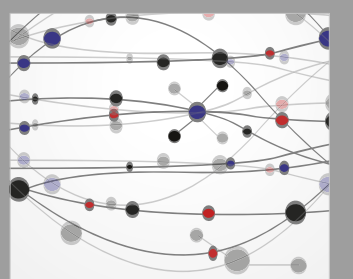

\section{Rotating \\ Machinery}

The Scientific World Journal

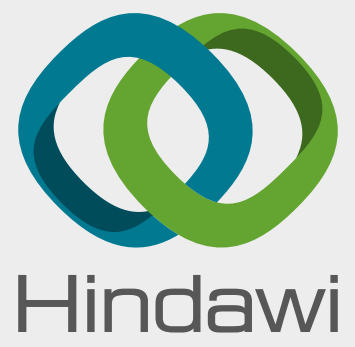

Submit your manuscripts at

www.hindawi.com
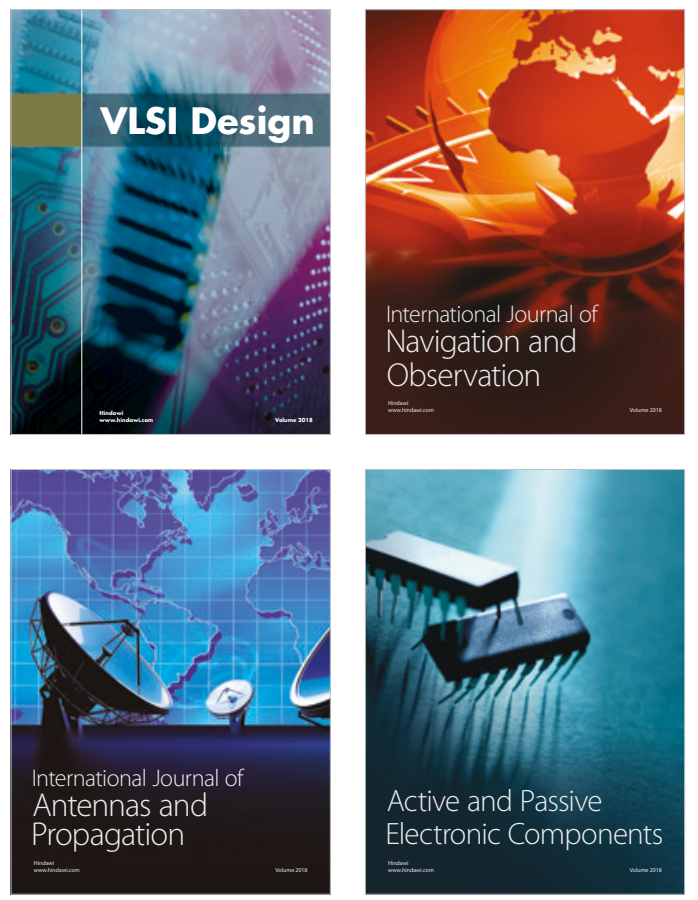
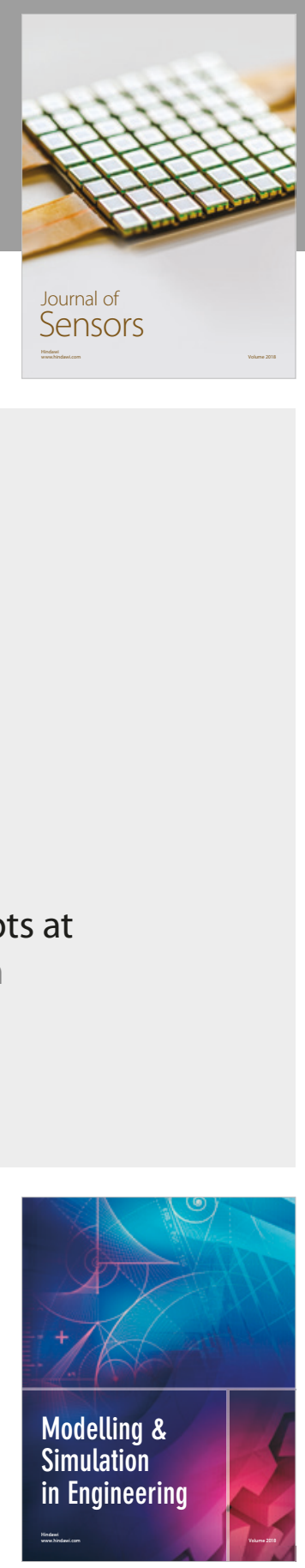

\section{Advances \\ Multimedia}
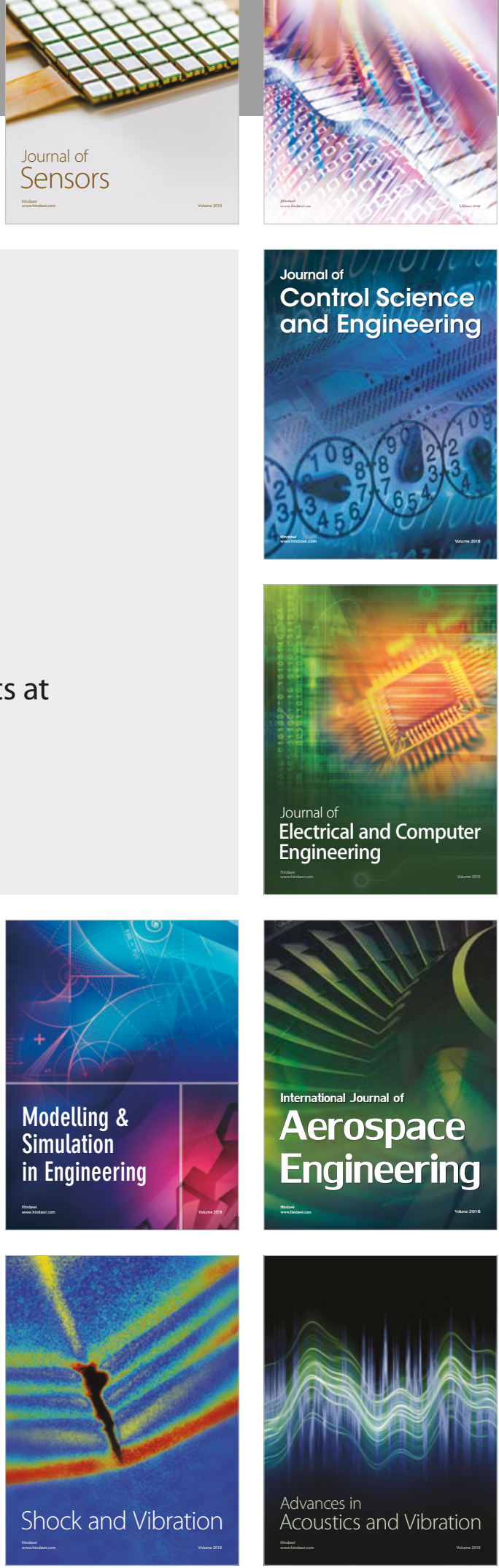